\title{
Consolidated bioprocessing of cellulose to itaconic acid by a co-culture of Trichoderma reesei and Ustilago maydis
}

\author{
Ivan Schlembach 1,2 ${ }^{1,}$ Hamed Hosseinpour Tehrani ${ }^{3}$, Lars M. Blank ${ }^{3}$, Jochen Büchs ${ }^{4}$, Nick Wierckx 3,5 , \\ Lars Regestein ${ }^{1}$ and Miriam A. Rosenbaum ${ }^{1,2^{*}}$ (D)
}

\begin{abstract}
Background: Itaconic acid is a bio-derived platform chemical with uses ranging from polymer synthesis to biofuel production. The efficient conversion of cellulosic waste streams into itaconic acid could thus enable the sustainable production of a variety of substitutes for fossil oil based products. However, the realization of such a process is currently hindered by an expensive conversion of cellulose into fermentable sugars. Here, we present the stepwise development of a fully consolidated bioprocess (CBP), which is capable of directly converting recalcitrant cellulose into itaconic acid without the need for separate cellulose hydrolysis including the application of commercial cellulases. The process is based on a synthetic microbial consortium of the cellulase producer Trichoderma reesei and the itaconic acid producing yeast Ustilago maydis. A method for process monitoring was developed to estimate cellulose consumption, itaconic acid formation as well as the actual itaconic acid production yield online during co-cultivation.

Results: The efficiency of the process was compared to a simultaneous saccharification and fermentation setup (SSF). Because of the additional substrate consumption of T. reesei in the CBP, the itaconic acid yield was significantly lower in the CBP than in the SSF. In order to increase yield and productivity of itaconic acid in the CBP, the population dynamics was manipulated by varying the inoculation delay between T. reesei and U. maydis. Surprisingly, neither inoculation delay nor inoculation density significantly affected the population development or the CBP performance. Instead, the substrate availability was the most important parameter. U. maydis was only able to grow and to produce itaconic acid when the cellulose concentration and thus, the sugar supply rate, was high. Finally, the metabolic processes during fed-batch CBP were analyzed in depth by online respiration measurements. Thereby, substrate availability was again identified as key factor also controlling itaconic acid yield. In summary, an itaconic acid titer of $34 \mathrm{~g} / \mathrm{L}$ with a total productivity of up to $0.07 \mathrm{~g} / \mathrm{L} / \mathrm{h}$ and a yield of $0.16 \mathrm{~g} / \mathrm{g}$ could be reached during fed-batch cultivation.
\end{abstract}

Conclusion: This study demonstrates the feasibility of consortium-based CBP for itaconic acid production and also lays the fundamentals for the development and improvement of similar microbial consortia for cellulose-based organic acid production.

Keywords: Consolidated bioprocessing, Itaconic acid, Platform chemical, Microbial consortium, Mixed culture, Co-culture, Cellulose, Lignocellulose, Simultaneous saccharification and fermentation, Metabolic engineering

*Correspondence: miriam rosenbaum@leibniz-hki.de

${ }^{1}$ Leibniz Institute for Natural Product Research and Infection Biology Hans-Knöll-Institute, Jena, Germany

Full list of author information is available at the end of the article

\section{Introduction}

Itaconic acid (IA) is a bio-derived platform chemical with various uses ranging from polymer synthesis to biofuel production. At the current selling price of $1500-1700$ USD/ton, itaconic acid is already becoming competitive 
to replace fossil polyacrylic acid in the production of superabsorbent polymers $[1,2]$. Still, to access other bulk markets like methyl methacrylate, which is currently produced from acetone cyanohydrin (about 1000 USD/ton), the price of itaconic acid has to drop further. Besides reducing the processing costs, the price of itaconic acid can be further reduced by using cheaper substrates. For comparison, the current sugar prices are about 310 USD/ ton while pulp grade wood costs only about $35 \mathrm{USD} /$ ton
$[3,4]$. The cheap and sustainable production of itaconic acid from cellulosic waste streams is therefore a highly anticipated goal of current research $[5,6]$.

The biosynthesis of itaconic acid in the filamentous fungus Aspergillus terreus is directly derived from the Krebs cycle, where it is produced from cis-aconitate by decarboxylation via its key biosynthetic enzyme cisaconitate decarboxylase (Fig. 1) [7]. The yeast Ustilago maydis in contrast, first isomerizes the cis-aconitate to

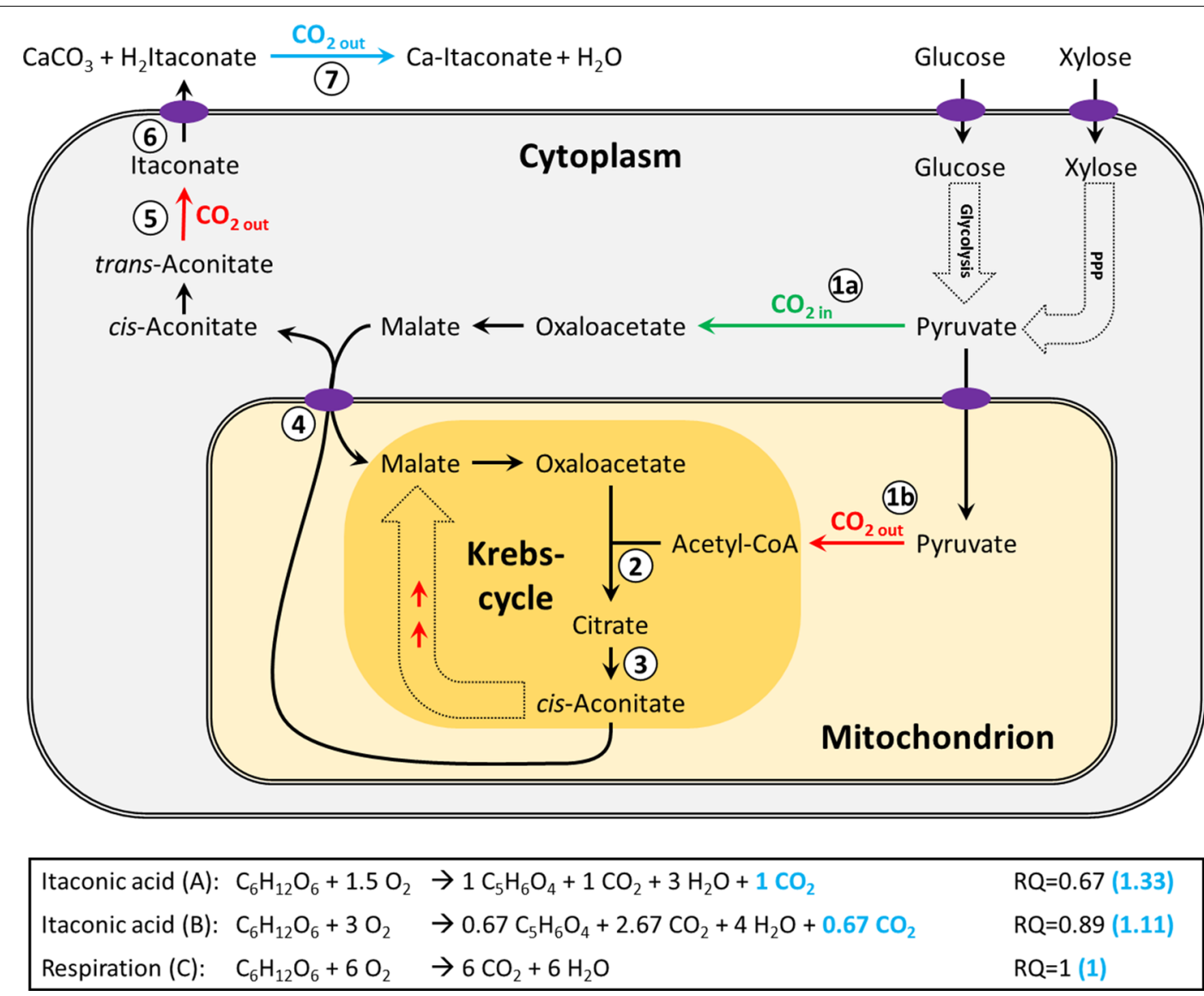

Fig. 1 Biosynthesis of itaconic acid. Glucose is taken up from the medium and converted into pyruvate via glycolysis. Pentose sugars are converted to pyruvate via pentose phosphate pathway (PPP). Box shows the reaction stoichiometry and resulting respiratory quotients (RQ) using different pathways: Pathway a: To reach the maximum theoretical yield of $1 \mathrm{~mol} / \mathrm{mol}$ glucose, itaconic synthesis must involve anaplerotic $\mathrm{CO}_{2}$ fixation: for each mol of glucose, $1 \mathrm{~mol}$ of the produced pyruvate is transported to the mitochondrion and 1 mol of pyruvate is converted to malate in the cytosol (1a). In the mitochondrion, pyruvate is converted to acetyl-CoA (1 b) and further to citrate by citrate synthase (2) using oxaloacetate. Citrate is then converted into cis-aconitate by aconitase (3). Via a mitochondrial tricarboxylate-malate shuttle (4), cis-aconitate is exported to the cytosol in exchange for malate, which replenishes the oxaloacetate used for citrate synthesis. In the cytosol cis-aconitate is then directly decarboxylated to itaconic acid by cis-aconitate decarboxylase (5) in the case of A. terreus or first isomerized into transaconitate before being decarboxylated in the case of $U$. maydis. Finally, itaconic acid is exported outside the cell (6). The respiratory quotient for this pathway would be 0.67 . Pathway $\mathbf{b}$ : If itaconic acid is produced without anaplerotic $\mathrm{CO}_{2}$ fixation, the pathway has to be exclusively fed from acetyl-CoA (1a). In this case, the spent $\mathrm{C} 4$ acids such as oxaloacetate also have to be replenished by reactions relying on acetyl-CoA. Hence, $1 / 3$ of the carbon is lost into $\mathrm{CO}_{2}$ at pyruvate decarboxylase step, which is why a minimum of $1.5 \mathrm{~mol}$ of glucose will then be needed for producing 1 mol of itaconic acid, resulting in a maximum yield of $0.67 \mathrm{~mol} / \mathrm{mol}$ glucose. The respiratory quotient for this pathway would be 0.89 . Pathway $\mathbf{c}$ : The $R Q$ for respiration biomass formation can be considered to be 1. Depending on the share of substrate used for respiration or biomass formation, the itaconic acid yield can be anywhere between 0 and $1 \mathrm{~mol} / \mathrm{mol}$ glucose while the corresponding respiratory quotient would be between 1 and 0.67 , respectively. However, when $\mathrm{CaCO}_{3}$ is used in the medium, the itaconic acid will react to calcium itaconate once exported outside the cell, which releases an additional mol of $\mathrm{CO}_{2}(7)$. This leads to an apparent RQ between 1 and 1.33 for pathways $\mathbf{a}-\mathbf{c}$, depending on the itaconic acid production yield. The apparent quotient when using $\mathrm{CaCO}_{3}$ is shown in blue letters. 
trans-aconitate before decarboxylation [8]. Depending on the production yield and the involved metabolic reactions, the biosynthesis of itaconic acid has different implications on the respiratory quotient, which can be exploited to analyze its production non-invasively via offgas measurements, as described in Fig. 1.

Currently, industrial itaconic acid production is exclusively realized by a fermentation process using the filamentous fungus Aspergillus terreus [9]. However, itaconic acid production with $A$. terreus is a challenging process that is only efficient if certain prerequisites are fulfilled. These prerequisites are a high initial sugar concentration, a low fermentation $\mathrm{pH}$, a strict manganese deficiency and a non-interrupted oxygen supply [10-12]. These prerequisites have been found especially difficult to be fulfilled in the context of cellulose-based itaconic acid production $[13,14]$ :

The bioconversion of cellulose into itaconic acid as well as other bio-commodities generally involves a hydrolysis of the cellulose into soluble sugars followed by a fermentation of the released sugars into the targeted product. This process configuration is called separate hydrolysis and fermentation (SHF). Recent attempts to produce itaconic acid in an SHF approach failed mainly because of manganese and other impurities contained in both the cellulose feedstock as well as in cellulase enzyme preparations used for hydrolysis [15]. Until now, production of cellulosic itaconic acid had been only proven successful after extensive purification of the cellulose hydrolysate using ion exchangers or activated charcoal [16-18], which impacts the economy of the process. Table 1 shows a summary of all known attempts on cellulose-based itaconic acid production available from literature. A strategy that has the potential to substantially increase the process economy is simultaneous saccharification and fermentation (SSF). This concept has the great advantage that the inherent inhibition of the cellulases by their hydrolysis products is completely avoided, since the released sugars are constantly consumed during the process. However, while sugars should not accumulate during SSF to prevent product inhibition of cellulases, high sugar concentrations are a prerequisite for efficient itaconic acid production using $A$. terreus $[10,13,15,19$, 20]. Therefore, this process configuration is not suitable with $A$. terreus as a biocatalyst [15]. Another obstacle for an A. terreus-based SSF is the required low fermentation $\mathrm{pH}$ of 3.4-1.8, which is incompatible with the $\mathrm{pH}$ activity profile of conventional cellulases ( $\mathrm{pH} 4-6.5)$.

Ustilago maydis is a promising alternative itaconic acid producer, which is capable of producing itaconate at a more neutral $\mathrm{pH}$ range (4.5-6.5) and with lower initial sugar concentrations. Furthermore, $U$. maydis is completely insensitive to manganese, which renders it much more suitable for the conversion of non-purified cellulose feedstocks. It has a single cell yeast morphology, which improves fermentation broth rheology and thereby facilitates efficient aeration in comparison to shear-sensitive fungi pellets [14, 21]. In addition, in terms of biosafety, $U$. maydis is classified as biosafety level 1 and can be even consumed as a food delicacy while $A$. terreus is an opportunistic human pathogen and has recently been classified into biosafety level 2 in some countries, which considerably restricts its use [22].

$U$. maydis has already proven suitable for SSF-based itaconic acid production, however reaching only very low yields despite application of high cellulase loadings of $0.1 \mathrm{~g}_{\text {Protein }} / \mathrm{g}_{\text {Cellulose }}$ or 26 filter paper units (FPU)/

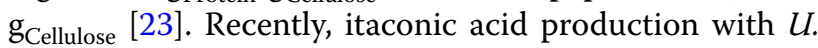
maydis and other Ustilaginaceae such as $U$. cynodontis has been improved considerably by genetic engineering [24-27]. This, along with advances in bioprocess design enabled by the yeast morphology [27-29], has considerably enhanced the yield, titer, and rate of itaconic acid production by Ustilago.

A yet unachieved goal is the direct conversion of cellulose into itaconic acid without application of externally produced enzymes in a fully consolidated bioprocess (CBP). Although both A. terreus and $U$. maydis naturally possess biomass-hydrolysing enzymes [30-32], neither of the organisms is known to produce itaconic acid when grown on cellulose. Furthermore, their cellulase activity is far too low for efficient itaconic acid production from cellulose. To realize a CBP, different strategies are possible. One approach that has been realized recently is the genetic modification of a native cellulolytic organism like Neurospora crassa to enable the synthesis of itaconic acid. However, only $0.02 \mathrm{~g} / \mathrm{L}$ of itaconic acid were produced from $20 \mathrm{~g} / \mathrm{L}$ corn stover [33]. In general, the recombinant production of itaconic acid in non-native hosts has been proven challenging. Even the conversion of the citric acid producer $A$. niger, which is closely related to $A$. terreus, into an effective itaconic acid producer seems to be difficult [34-36]. Alternatively, a native itaconic acid producer could be engineered to produce carbohydrate-active enzymes, either by activation of dormant native genes [37, 38], or by heterologous expression [39]. However, this is no straightforward task as it often involves the high-level expression and secretion of multiple enzymes [40, 41]. A third strategy, which has the potential to unite both the benefits of native cellulase producers, and the high production capability of dedicated organisms for the target product synthesis, is co-culture fermentation. Due to synergistic effects of labor division, the performance of a co-culture can even be greater than the sum of the individual sub processes [42]. This strategy has already been proven successful 
Table 1 Attempts for cellulose-based itaconic acid production in literature

\begin{tabular}{|c|c|c|c|c|c|c|c|c|}
\hline \multirow{2}{*}{$\begin{array}{c}\text { Process } \\
\text { configuration }\end{array}$} & \multirow[b]{2}{*}{ Key process determinant ${ }^{\#}$} & \multicolumn{3}{|c|}{ Achieved } & \multirow[b]{2}{*}{ Organism } & \multirow[b]{2}{*}{ Cellulase loading } & \multirow[b]{2}{*}{ Substrate } & \multirow[b]{2}{*}{ Publication } \\
\hline & & $\begin{array}{l}\text { Titer } \\
{[\mathrm{g} / \mathrm{L}]}\end{array}$ & $\begin{array}{l}\text { Yield } \\
{[\mathrm{g} / \mathrm{g}]^{*}}\end{array}$ & $\begin{array}{l}\text { Productivity } \\
{[\mathrm{g} / \mathrm{L} / \mathrm{h}]^{\S}}\end{array}$ & & & & \\
\hline $\begin{array}{l}\text { Glucose fed- } \\
\text { batch }\end{array}$ & $\begin{array}{l}\text { Productivity focused } \\
\text { Yield focused }\end{array}$ & $\begin{array}{l}160 \\
160\end{array}$ & $\begin{array}{l}0.46 \\
0.58\end{array}$ & $\begin{array}{l}0.99 \\
0.57\end{array}$ & $\begin{array}{l}\text { A. terreus } \\
\text { DSM } 23081\end{array}$ & - & Glucose & (46) \\
\hline $\begin{array}{l}\text { Glucose fed- } \\
\text { batch }\end{array}$ & $\begin{array}{l}\text { Productivity focused } \\
\text { Yield focused }\end{array}$ & $\begin{array}{l}220 \\
140\end{array}$ & $\begin{array}{l}0.33 \\
0.39\end{array}$ & $\begin{array}{l}0.45 \\
0.32\end{array}$ & $\begin{array}{c}\text { U. maydis } \Delta c y p 3 \\
\Delta P_{\text {ria } 1}:: P_{\text {etef }} \Delta f u z 7 \\
P_{\text {etef }} m t t A\end{array}$ & - & Glucose & (28) \\
\hline SHF & $\begin{array}{l}\text { Hydrolysate purification: } \\
\text { cation + anion exchange } \\
\text { resin }\end{array}$ & 7.2 & 0.3 & 0.1 & $\begin{array}{l}\text { A. terreus } \\
\text { NRRL } 1960\end{array}$ & $\begin{array}{c}5 \mathrm{FPU} / \mathrm{g} \\
\text { Cellic CTec2 }\end{array}$ & $\begin{array}{l}\text { Organosolv } \\
\text { beech wood }\end{array}$ & (16) \\
\hline \multirow{3}{*}{ SHF } & $\begin{array}{l}\text { No hydrolysate } \\
\text { purification }\end{array}$ & 2.1 & n.d. & n.d. & \multirow{3}{*}{$\begin{array}{l}\text { A. terreus } \\
\text { DSM } 23081\end{array}$} & \multirow{3}{*}{$\begin{array}{c}10 \mathrm{FPU} / \mathrm{g} \\
\text { Biogazyme } 2 \mathrm{X}\end{array}$} & \multirow{3}{*}{$\begin{array}{c}\text { Alkaline } \\
\text { pretreated wheat } \\
\text { chaff }(100 \mathrm{~g} / \mathrm{L})\end{array}$} & \multirow{3}{*}{ (15) } \\
\hline & $\begin{array}{l}\text { Hydrolysate concentration } \\
\text { and protein precipitation }\end{array}$ & 23.3 & 0.27 & 0.16 & & & & \\
\hline & $\begin{array}{l}\text { Hydrolysate purification: } \\
\text { cation exchange resin }\end{array}$ & 27.7 & 0.41 & 0.19 & & & & \\
\hline SHF & $\begin{array}{c}\text { Hydrolysate purification: } \\
\text { activated charcoal } \\
\text { treatment }\end{array}$ & 33.6 & 0.56 & 0.28 & $\begin{array}{l}\text { A. terreus } \\
\text { M69 }\end{array}$ & $\begin{array}{l}9.3 \mathrm{FPU} / \mathrm{g} \\
\text { Cellic CTec2 }\end{array}$ & $\begin{array}{l}\text { Corn stover } \\
(150 \mathrm{~g} / \mathrm{L})\end{array}$ & (17) \\
\hline SHF & $\begin{array}{l}\text { Inhibitor tolerant } \\
\text { A. terreus mutant }\end{array}$ & 19.3 & 0.36 & 0.16 & $\begin{array}{l}\text { A. terreus } \\
\text { AT-90 }\end{array}$ & $20 \mathrm{FPU} / \mathrm{g}$ & $\begin{array}{l}\text { Steam exploded } \\
\text { corn stover (100 } \\
\mathrm{g} / \mathrm{L})\end{array}$ & (47) \\
\hline SHF & $\begin{array}{c}\text { No Hydrolysate } \\
\text { purification; } \\
\text { bleached pulp }\end{array}$ & 27.6 & 0.52 & 0.4 & $\begin{array}{l}\text { A. terreus } \\
\text { NRRL } 1960\end{array}$ & $10 \mathrm{FPU} / \mathrm{g}$ & $\begin{array}{c}\text { Bleached } \\
\text { eucalyptus pulp } \\
(120 \mathrm{~g} / \mathrm{L})\end{array}$ & (20) \\
\hline SHF & $\begin{array}{c}\text { Hydrolysate purification: } \\
\text { activated charcoal } \\
\text { treatment }\end{array}$ & 49.7 & 0.55 & 0.41 & $\begin{array}{l}\text { A. terreus } \\
\text { CICC } 40205\end{array}$ & Sulfuric acid hydrolysis & $\begin{array}{l}\text { Wheat bran } \\
\text { hydrolysate }\end{array}$ & (18) \\
\hline SHF & \multirow{2}{*}{$\begin{array}{l}\text { A. terreus mutant }+ \\
\text { addition of corn steep } \\
\text { liquor }(2 \mathrm{~g} / \mathrm{L})\end{array}$} & 19.35 & 0.36 & 0.16 & \multirow{2}{*}{$\begin{array}{l}\text { A. terreus } \\
\text { AtYSZ-38 }\end{array}$} & \multirow[b]{2}{*}{$20 \mathrm{FPU} / \mathrm{g}$} & $\begin{array}{c}\text { Bamboo } \\
\text { (100 g/L) }\end{array}$ & \multirow[b]{2}{*}{ (48) } \\
\hline SHF fed-batch & & 41.54 & 0.28 & 0.16 & & & $\begin{array}{l}\text { Bamboo } \\
\text { hydrolysate } \\
\text { (150 g/L) }\end{array}$ & \\
\hline SSF & $\begin{array}{l}\text { No Hydrolysate } \\
\text { purification }\end{array}$ & 2.5 & n.d. & n.d. & $\begin{array}{l}\text { A. terreus } \\
\text { DSM } 23081\end{array}$ & $\begin{array}{c}10 \mathrm{FPU} / \mathrm{g} \\
\text { Biogazyme } 2 \mathrm{X}\end{array}$ & $\begin{array}{c}\text { Alkaline } \\
\text { pretreated wheat } \\
\text { chaff }(100 \mathrm{~g} / \mathrm{L})\end{array}$ & (15) \\
\hline SSF & U. maydis & 4.71 & 0.12 & n.d. & $\begin{array}{l}\text { U. maydis } \\
\text { MB215 }\end{array}$ & $\begin{array}{l}26 \mathrm{FPU} / \mathrm{g} \\
\text { Celluclast }\end{array}$ & $\begin{array}{c}\alpha \text {-cellulose } \\
(60 \mathrm{~g} / \mathrm{L})\end{array}$ & (23) \\
\hline SSF & $\begin{array}{l}\text { A. terreus mutant }+ \\
\text { addition of corn steep } \\
\text { liquor }(2 \mathrm{~g} / \mathrm{L})\end{array}$ & 22.43 & n.d. & 0.23 & $\begin{array}{l}\text { A. terreus } \\
\text { AtYSZ-38 }\end{array}$ & $20 \mathrm{FPU} / \mathrm{g}$ & $\begin{array}{l}\text { Bamboo } \\
(100 \mathrm{~g} / \mathrm{L})\end{array}$ & (48) \\
\hline \multirow[t]{2}{*}{ SSF } & \multirow[t]{2}{*}{$\begin{array}{l}\text { Optimizted } U . \text { maydis } \\
\text { strain }\end{array}$} & $\begin{array}{l}19 \\
7\end{array}$ & 0.20 & 0.188 & \multirow[t]{2}{*}{$\begin{array}{c}\text { U. maydis } \\
\Delta c y p 3 \Delta P_{\text {ria } 1:: P_{\text {etef }}} \\
\Delta \text { fuz7 } P_{\text {etef }} m t t A\end{array}$} & $\begin{array}{c}18 \mathrm{FPU} / \mathrm{g} \\
\text { (diluted } T . \text { reesei) } \\
5 \mathrm{FPU} / \mathrm{g} \\
\text { (diluted } \mathrm{P} \text {. verruculosum) }\end{array}$ & $\begin{array}{c}\alpha \text {-cellulose } \\
(180 \mathrm{~g} / \mathrm{L})\end{array}$ & \multirow[t]{2}{*}{ This study } \\
\hline & & 15.3 & 0.381 & 0.093 & & $\begin{array}{c}35 \mathrm{FPU} / \mathrm{g} \\
\text { (non-diluted } T \text {. reesei) }\end{array}$ & $\begin{array}{c}\alpha \text {-cellulose } \\
(120 \mathrm{~g} / \mathrm{L})\end{array}$ & \\
\hline CBP batch & Heterologous expression & 0.02 & n.d. & n.d. & N. crassa & $15 \mathrm{FPU} / \mathrm{g}$ & $\begin{array}{c}\text { Avicel } \\
\text { (20 g/L) }\end{array}$ & (33) \\
\hline CBP batch & \multirow{2}{*}{$\begin{array}{l}\text { Defined co-culture of } \\
\text { optimizted } U . \text { maydis } \\
\text { strain with } T \text {. reesei }\end{array}$} & 10.5 & 0.134 & 0.064 & \multirow{2}{*}{$\begin{array}{c}\text { U. maydis } \\
\Delta c y p 3 \Delta P_{\text {ria } 1}:: P_{\text {etef }} \\
\Delta \text { fuz7 } P_{\text {etef }} m t t A \\
+T . \text { reesei } \\
\text { RUT-C30 }\end{array}$} & $35 \mathrm{FPU} / \mathrm{g}$ & $\begin{array}{c}\alpha \text {-cellulose } \\
(120 \mathrm{~g} / \mathrm{L})\end{array}$ & \multirow[b]{2}{*}{ This study } \\
\hline CBP fed-batch & & 33.8 & 0.156 & 0.07 & & $66 \mathrm{FPU} / \mathrm{g}$ & $\begin{array}{c}\alpha \text {-cellulose } \\
(270 \mathrm{~g} / \mathrm{L})\end{array}$ & \\
\hline
\end{tabular}

\# The key determinant to overcome the challenges associated with cellulose-based itaconic acid production. For reference, cases without specific adaptions are shown in red. *Yield is based on consumed glucose equivalents excluding cellulase production phase. ${ }^{\S}$ Averaged productivity excluding cellulase production phase. Glucose based reference datasets are shaded blue, results from this study are shaded green 
for the production of different bio-commodities such as isobutanol, lactic acid, and fumaric acid [43-45]. Therefore, here we aim to establish a CBP by co-cultivating the hyper cellulolytic fungus Trichoderma reesei RUT-C30 (RFP1) with the engineered $U$. maydis $\Delta c y p 3 \Delta P_{\text {rial }}: P_{\text {etef }}$ $\Delta f u z 7 P_{\text {etef }} m t t A$ for itaconic acid production.

\section{Results and discussion}

\section{Simultaneous saccharification and fermentation (SSF)}

As a first step towards consolidated bioprocessing, itaconic acid production was assessed in a SSF setup to evaluate the capability of the engineered $U$. maydis $\Delta c y p 3 \Delta P_{\text {rial } 1:} P_{\text {etef }} \Delta f u z 7 P_{\text {etef }} m t t A$ to produce itaconic acid under glucose-limiting conditions. Thereby, fermentation supernatants of two different cellulolytic fungi ( $T$. reesei RUT-C30 (RFP1) and Penicillium verruculosum (M28-10) were compared as source for cellulases. These fungi have been found compatible with the presence of itaconic acid in a previous screening [49]. Since nitrogen limitation is a prerequisite for itaconic acid production with $U$. maydis, the residual $\mathrm{NH}_{4}{ }^{+}$-concentration present in the cellulase-containing supernatants had to be monitored [50]. The supernatants were diluted accordingly to reach a final $\mathrm{NH}_{4}{ }^{+}$-concentration equivalent to the $0.8 \mathrm{~g} / \mathrm{L} \mathrm{NH}_{4} \mathrm{Cl}$, typically present in itaconic acid production medium for $U$. maydis $[26,28,29]$. This resulted in a final cellulase titer of $2.2 \mathrm{FPU} / \mathrm{mL}$ for the cultivations containing $T$. reesei supernatant and $0.6 \mathrm{FPU} / \mathrm{mL}$ for the cultivations containing P. verruculosum supernatant. These values corresponded to 18 and $5 \mathrm{FPU} / \mathrm{g}$ cellulose, respectively, and are close to the cellulase loading of $10 \mathrm{FPU} / \mathrm{g}$ cellulose, typically used for separate cellulose hydrolysis [51]. Since cellulose digestibility has a major impact on cellulose hydrolysis, $120 \mathrm{~g} / \mathrm{L}$ of highly digestible Sigmacell as well as $120 \mathrm{~g} / \mathrm{L}$ recalcitrant $\alpha$-cellulose were tested as substrates [52]. All media were buffered to pH 6.5 using $100 \mathrm{mM}$ MES buffer.

As shown in Fig. 2, both T. reesei and $P$. verruculosum supernatants enabled itaconic acid production from cellulose by $U$. maydis during SSF. Using the T. reesei supernatant, similar itaconic acid concentrations as in a reference culture containing $50 \mathrm{~g} / \mathrm{L}$ of glucose instead of cellulose were reached. The highest itaconic acid concentration achieved during the SSF was $21 \mathrm{~g} / \mathrm{L}$ using Sigmacell as substrate, which is fourfold higher than previously demonstrated for a SSF using wildtype $U$. maydis MB215, and close to the values achieved with $A$. terreus (Table 1). Even using the relatively recalcitrant $\alpha$-cellulose, a similar titer of $19 \mathrm{~g} / \mathrm{L}$ itaconic acid was produced. Although the itaconic acid production using the $P$. verruculosum supernatant was generally lower than using $T$. reesei supernatant, especially with $\alpha$-cellulose, the achieved titers were still considerable in relation to the almost fourfold lower cellulase activity of $0.6 \mathrm{FPU} / \mathrm{mL}$. Remarkably, the itaconic acid yield based on the consumed amount of glucose equivalents from cellulose was essentially identical to the yield achieved using glucose in the reference and also comparable to yields achieved with $A$. terreus using purified cellulose hydrolysate (Table 1).

From the $\mathrm{pH}$ profile, it can be seen that in most of the cultures the $\mathrm{pH}$ dropped to about 3.5 after $69 \mathrm{~h}$ of cultivation. Since it is known that $U$. maydis stops itaconic acid production at such low $\mathrm{pH}$ values [53], it is possible that higher itaconic acid titers could have been achieved using a higher buffer concentration or active $\mathrm{pH}$ control, which would also have further improved the cellulose hydrolysis. This hypothesis was confirmed by comparing the itaconic acid production of glucose-supplemented SSF cultures either buffered with MES or with $\mathrm{CaCO}_{3}$ (Additional file 1: Fig. S1). In case of the MES-buffered culture, itaconic acid production stopped before the exhaustion of glucose when reaching $\mathrm{pH}$ 3.5. In contrast, the $\mathrm{CaCO}_{3}$-buffered culture that maintained $\mathrm{pH}$ between 6 and 7 continued itaconic acid production after exhaustion of the added glucose and further converted cellulose into itaconic acid. An added benefit of the $\mathrm{CaCO}_{3}$ addition is an in situ precipitation of the product as calcium itaconate, which alleviates product inhibition and facilitates downstream processing [28]. Calcium salt precipitation still belongs to the most mature and widely applied downstream technology for industrial organic acid production $[28,54]$.

\section{Consolidated bioprocessing (CBP) with co-cultures of $T$. reesei and $U$. maydis}

As a next step, itaconic acid production was assessed in a CBP setup with a sequential co-culture of $U$. maydis and T. reesei. First, T. reesei was grown for 1 week in pure culture to produce sufficient cellulase enzymes, whereafter $U$. maydis was added to an OD of 0.67 . To prevent a termination of itaconic acid production due to a decreasing $\mathrm{pH}$, the medium was buffered with $33 \mathrm{~g} / \mathrm{L} \mathrm{CaCO}_{3}$. The performance of the CBP culture was directly compared to a corresponding SSF culture using undiluted sterile filtered supernatant of the same $T$. reesei pre-culture used for CBP. A schematic representation of the experimental setup is depicted in Fig. 3.

As can be seen in Fig. 4a, up to $10.5 \mathrm{~g} / \mathrm{L}$ of itaconic acid was produced in the co-culture CBP. The SSF in contrast produced up to $15.3 \mathrm{~g} / \mathrm{L}$ of itaconic acid. Thus, the CBP was clearly less effective in producing itaconic acid than the SSF. This could be already expected since two organisms have to share the same resources. The cellulose consumption (Fig. 4e) was clearly higher in the CBP compared to the SSF, especially during the initial $72 \mathrm{~h}$ growth phase. Since all conditions are identical between CBP and 

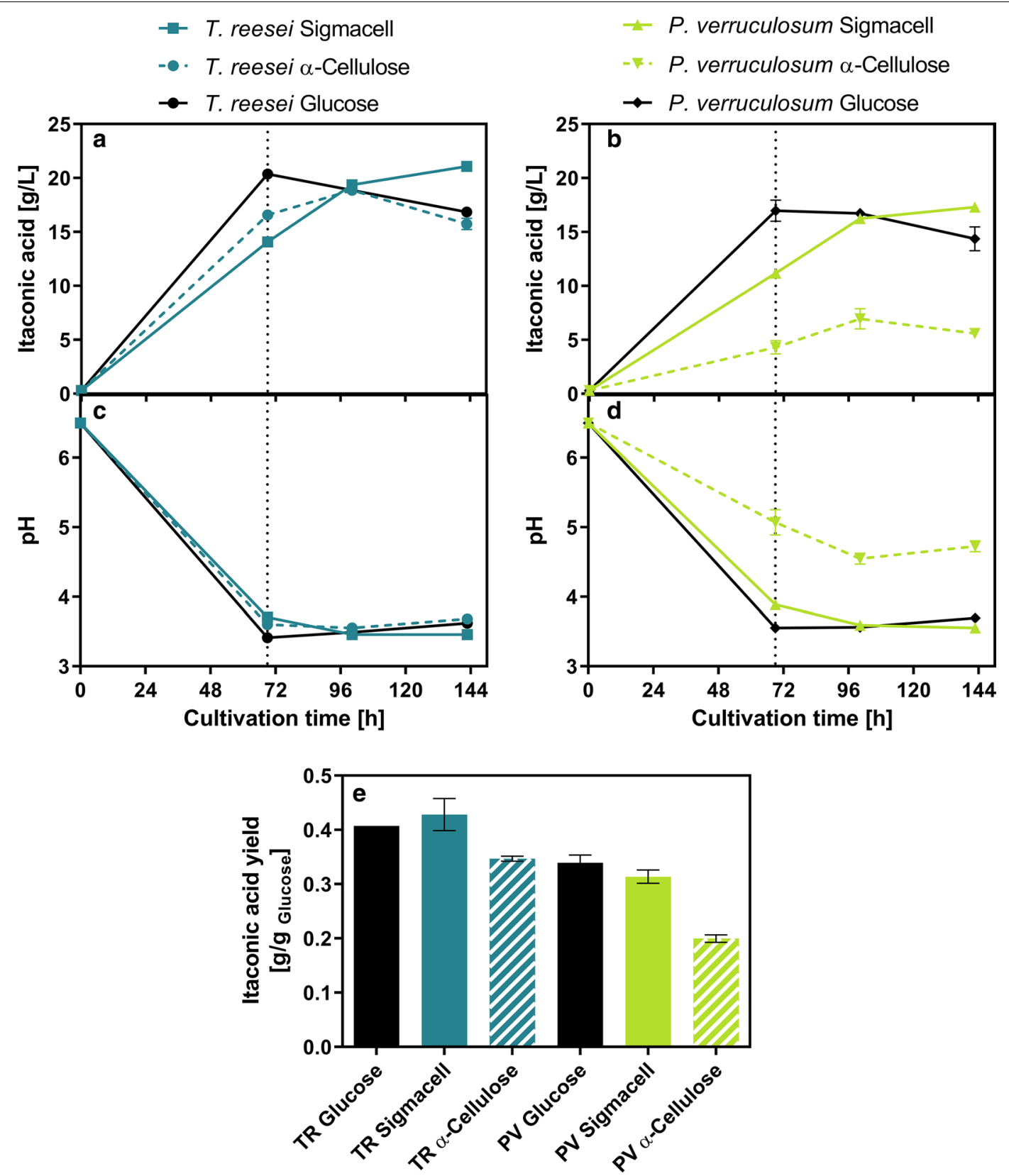

Fig. 2 SSF-based itaconic acid production using U. maydis $\Delta$ cyp3 $\Delta P_{\text {ria }}:: P_{\text {etef }} \Delta f$ fuz $7 P_{\text {etef }} m t t A$ with different cellulose substrates and sources of cellulases. a Shows the itaconic acid production during SSF using T. reesei (TR) enzymes (2.2 FPU/mL), b Shows the itaconic acid production during SSF using P. verruculosum (PV) enzymes (0.6 FPU/mL). c, d Show the corresponding pH profiles of the SSF cultures containing T. reesei or $P$. verruculosum enzymes, respectively. e Shows a comparison of the achieved itaconic acid production yields based on the consumed amount of glucose equivalents ( $1 \mathrm{~g}$ cellulose can yield $1.1 \mathrm{~g}$ glucose). Nitrogen-free itaconic acid production medium for U. maydis was supplemented with sterile filtered culture supernatants of T. reesei RUT-C30 (RFP1) or P. verruculosum M28-10. The residual $\mathrm{NH}_{4}^{+}$concentration in the culture supernatant was determined and the supernatants were diluted accordingly (1/5), so that the $\mathrm{NH}_{4}{ }^{+}$transferred from the cellulase-containing supernatants is equivalent to the $0.8 \mathrm{~g} / \mathrm{L} \mathrm{NH}_{4} \mathrm{Cl}$ which is usually added to the medium as nitrogen source. Both culture supernatants were combined with either $120 \mathrm{~g} / \mathrm{L}$ Sigmacell, $120 \mathrm{~g} / \mathrm{L}$ a-cellulose or $50 \mathrm{~g} / \mathrm{L}$ of glucose as a reference. The medium was buffered to $\mathrm{pH} 6.5$ using $100 \mathrm{mM}$ MES buffer. The

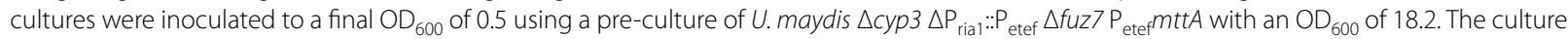
was performed with $25 \mathrm{~mL}$ filling volume in $250 \mathrm{~mL}$ Erlemeyer flasks at $200 \mathrm{rpm}, 50 \mathrm{~mm}$ shaking diameter and $30^{\circ} \mathrm{C}$. Values shown are means of biological duplicates, error bars show deviation from the mean. The $100 \mathrm{~h}$ time point only shows single measurments from one replicate. The dotted line indicates the additional feeding of $60 \mathrm{~g} / \mathrm{L}$ a-cellulose 


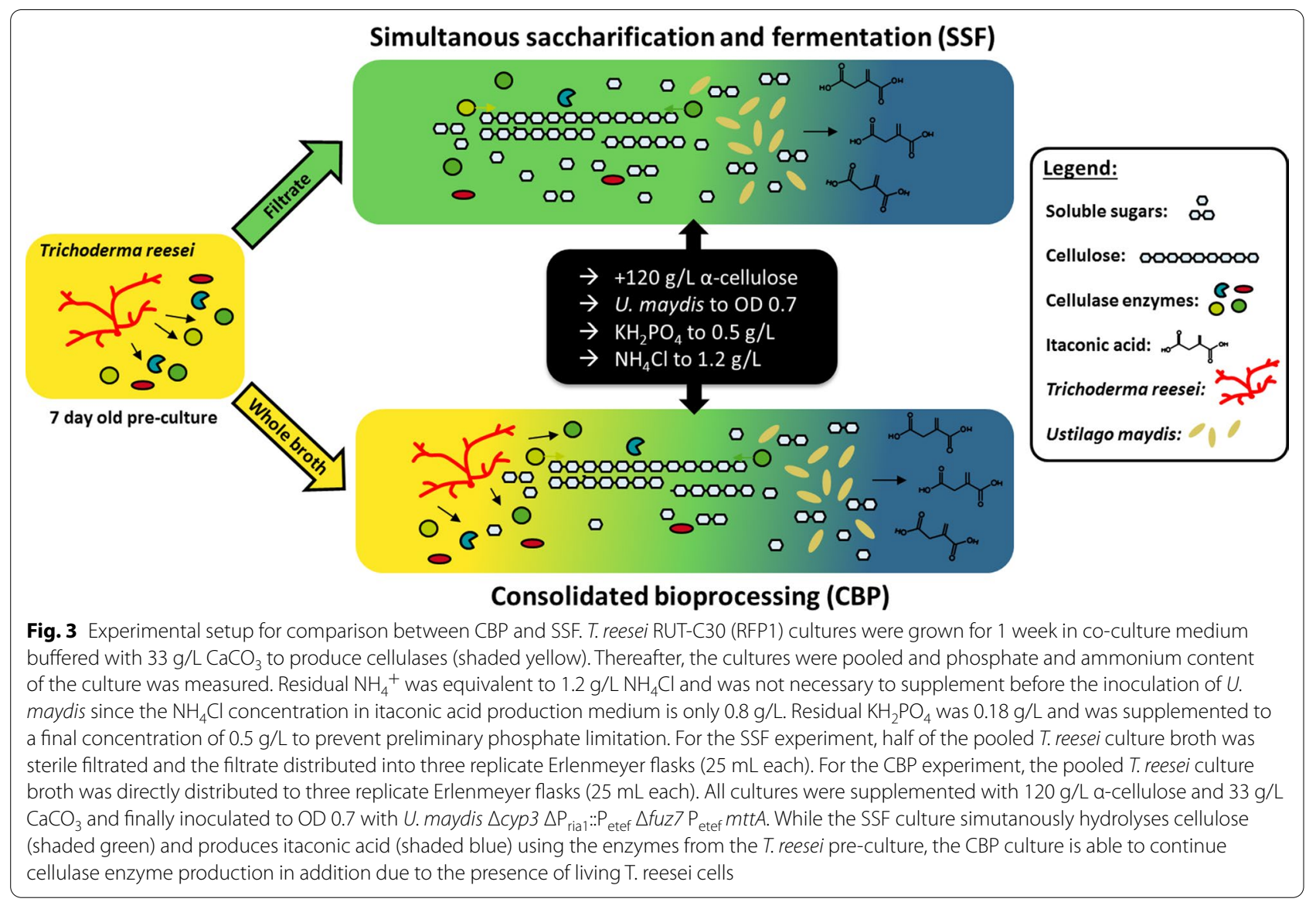

SSF except for the presence of living $T$. reese $i$ cells, this increase in cellulose consumption can be clearly attributed to $T$. reesei. In turn, also the itaconic acid yield was affected by the CBP in comparison to the SSF. While a yield of $0.381 \mathrm{~g} / \mathrm{g}$ Glucose was reached in the SSF, only $0.134 \mathrm{~g} / \mathrm{g}$ Glucose were achieved in the CBP.

On the positive side, this increased cellulose consumption also demonstrates an enhanced cellulose hydrolysis performance with increased metabolic substrate demand. A recent publication on cellulosic malic acid production demonstrated that an increase in metabolic activity can drastically enhance cellulose hydrolysis without increasing cellulase concentration [55]. Therefore, the main challenge for optimizing the CBP setup is to channel the substrate consumption towards $U$. maydis and minimize the activity of $T$. reesei during the itaconic acid production phase. Still, some low residual activity of $T$. reesei could be beneficial, since the cellulase activity was more stable in the CBP compared to the SSF (Fig. 4c, d). This was likely due to constant re-synthesis of degraded cellulases by $T$. reesei.

The population dynamics between $U$. maydis and $T$. reesei were not investigated in detail. Still, microscopic examination of the samples suggested a relatively balanced population ratio between $T$. reese $i$ and $U$. maydis towards the end of the culture. There were always cells visible from both $T$. reesei and $U$. maydis in randomly chosen fields of view (Fig. 5). The nitrogen supply in the cultures had to be limited in order to induce itaconic acid production by $U$. maydis. As a result of this limited nitrogen availability and competition with cellulase synthesis by $T$. reesei, both organisms could only grow until the shared nitrogen pool was exhausted. Hence, the $U$. maydis cell number per field of view was clearly lower in CBP compared to SSF, which might explain the lower itaconic acid productivity. If the nitrogen consumption of T. reese $i$ in the CBP would have been compensated by appropriate addition of $\mathrm{NH}_{4}{ }^{+}$, similar $U$. maydis cell densities and itaconic acid productivities might have been reached as in the SSF.

The major benefit of CBP in contrast to SSF is that no enzymes had to be added and that cellulose can directly be converted into itaconic acid. Since the targeted substrates are cellulosic waste streams, which have very low cost, the production yield is less important. It has to be evaluated whether the economic benefits of the CBP 

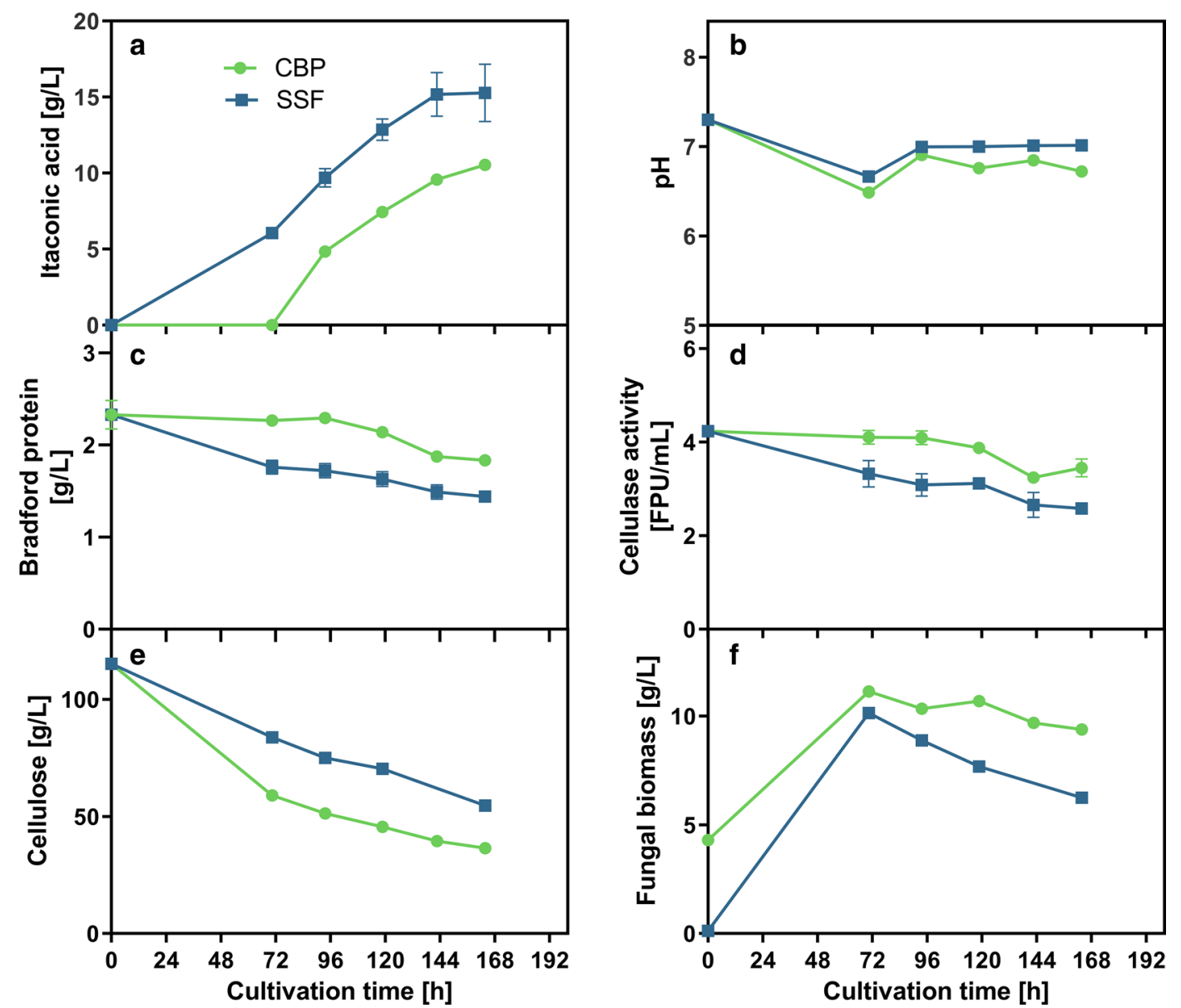

Fig. 4 Comparison of CBP and SSF of cellulose to itaconic acid using U. maydis and T. reesei. a Shows the itaconic acid production of U. maydis

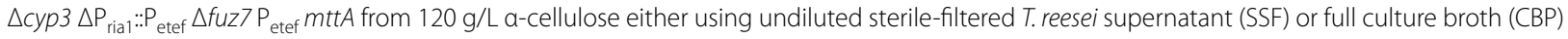
of a 1 week old pre-culture of T. reesei RUT-C30 (RFP1). b Shows the pH during cultivation. c Shows the protein concentration measured in the supernatant, which should correspond mainly to extracellular cellulases. $\mathbf{d}$ Shows the corresponding cellulase activity as measured by the filter paper assay. $\mathbf{e}$ Shows the residual cellulose concentration during the cultivation as determined by the Updegraff assay and $\mathbf{f}$ the corresponding dry weight of fungal biomass estimated from the weight loss during Updegraff assay. T. reesei RUT-C30 (RFP1) culture was grown for 1 week for cellulase production and then sterile filtered or directly used for the CBP experiment. The filtrate and the full culture broth were subsequently supplemented with $120 \mathrm{~g} / \mathrm{L}$ a-cellulose, $0.32 \mathrm{~g} / \mathrm{L} \mathrm{KH}_{2} \mathrm{PO}_{4}, 33 \mathrm{~g} / \mathrm{L} \mathrm{CaCO}_{3}$ and finally inoculated to a final $\mathrm{OD}_{600}$ of $0.67 \mathrm{using}$ a pre-culture of U. maydis $\triangle$ cyp3 $\Delta \mathrm{P}_{\text {rial } 1:}: \mathrm{P}_{\text {etef }} \Delta$ fuz $7 \mathrm{P}_{\text {etef }} m \mathrm{mtt}$. The culture was performed with $25 \mathrm{~mL}$ filling volume in $250 \mathrm{~mL}$ Erlenmeyer flasks at $200 \mathrm{rpm}, 50 \mathrm{~mm}$ shaking diameter and $30^{\circ} \mathrm{C}$. Values shown for itaconic acid and $\mathrm{pH}$ are means of biological triplicates, error bars show standard deviation. For cellulase activity, bradford protein, residual cellulose and fungal biomass, samples from the triplicates were pooled in order to collect sufficient sample volume and to make accurate gravimetric measurements and therefore only single values could be measured. For c error bars show standard deviation of technical triplicates, for $\mathbf{d}$ deviation of the mean from technical duplicates. Collected data are only shown until $164 \mathrm{~h}$ of cultivation. Beyond $164 \mathrm{~h}$ of cultivation, accurate and representative sampling was not possible anymore due to the high viscosity and inhomogeneity of the cultivation broth. The full dataset can be found in the Additional file 2: "Numerical data"

process can compensate the yield loss. The outcome of this will most likely depend strongly on the price of cellulase enzyme production and cellulosic substrate.

\section{Influence of inoculation time}

During the proof of principle CBP described above, T. reesei was cultured for one week in pure culture to produce sufficient cellulase enzymes before adding $U$. maydis. However, a one week pre-cultivation phase considerably lowers the average productivity of the co-culture compared to the SSF scenario (Table 2). To further optimize the co-culture and increase the productivity, the effect of inoculation delay between $T$. reesei and $U$. maydis on the CBP performance was studied. Four different additional inoculation delays were tested: 0 days (direct co-inoculation at the beginning), 3, 4, and 5 days. 

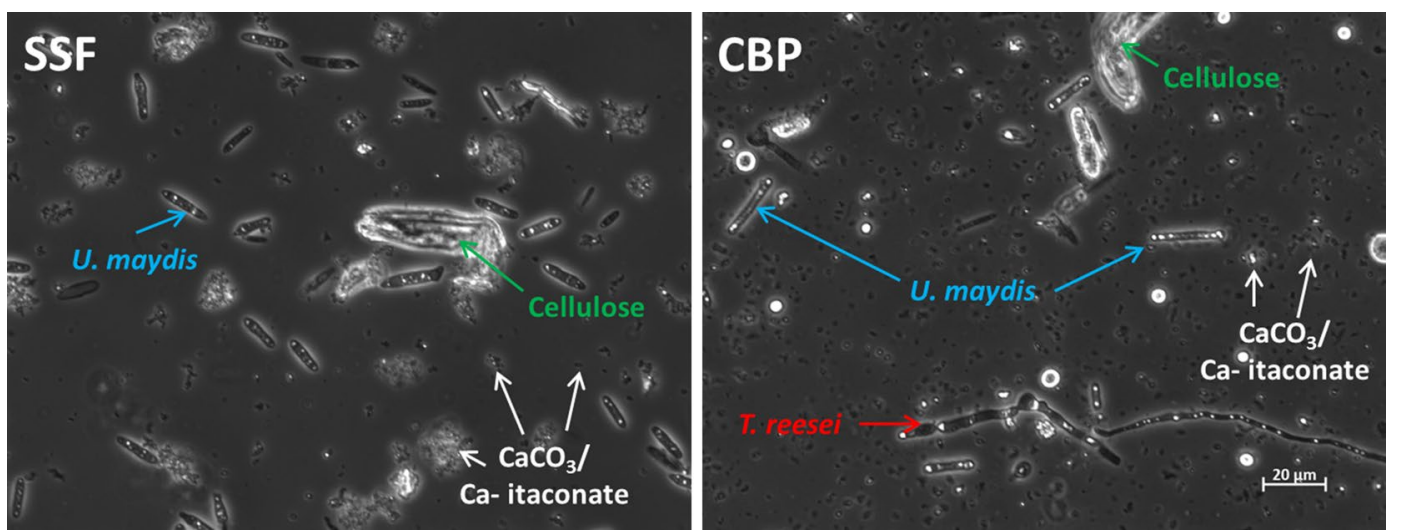

Fig. 5 Representative phase contrast microscopic image of SSF and CBP samples acquired after $164 \mathrm{~h}$ of cultivation. Samples were diluted 1/10 in distilled water before microscopy (400X magnification). Small particles are $\mathrm{CaCO}_{3}$

Table 2 Comparison of itaconic acid productivity between SSF and CBP fermentations

\begin{tabular}{lllll}
\hline & $\begin{array}{l}\text { Total duration } \\
\text { [h] }\end{array}$ & $\begin{array}{l}\text { Itaconic acid titer } \\
{[\mathbf{g} / \mathbf{L}]}\end{array}$ & $\begin{array}{l}\text { Averaged productivity } \\
\text { [g/L/h] }\end{array}$ & Source \\
\hline SSF & 164 & 15.3 & 0.093 & Figure 4 \\
CBP (itaconic acid phase only) & 164 & 10.5 & 0.064 & Figure 4 \\
CBP (including cellulase production) & 332 & 10.5 & 0.032 & Figure 6 \\
CBP fed-batch (itaconic acid phase only) & 478 & 33.8 & 0.071 & {$[3$ days delay] } \\
CBP fed-batch (including cellulase production) & 593 & 33.8 & 0.057 & Additional file 1: Figure S4 \\
Glucose fed-batch reference cultivation & 87 & 42.2 & 0.485 &
\end{tabular}

Because cellulase production by $T$. reesei usually starts after 2 days, it was expected that preliminary inoculation of $U$. maydis would strongly affect cellulase production due to competition for nitrogen. Therefore, 1 and 2 days delay were not tested. The experiment was performed in medium containing $5 \mathrm{~g} / \mathrm{L}$ glucose for initial growth acceleration and $30 \mathrm{~g} / \mathrm{L} \alpha$-cellulose. Furthermore, the experiment was carried out as fed-batch with regular feeding of $\alpha$-cellulose powder for maximization of itaconic acid production.

When $T$. reesei and $U$. maydis were co-inoculated, the culture did not produce any cellulase enzymes nor any itaconic acid. Instead, exclusively $U$. maydis grew and consumed all glucose before $T$. reese $i$ was able to germinate, thereby preventing the production of cellulases that would have enabled further growth of both organisms on cellulose. Because of the limited initial glucose concentration, a nitrogen limitation could not be reached, which explains the lack of itaconic acid production. Co-inoculation with vital cells of $T$. reesei instead of $T$. reesei spores might solve this problem since a starting quantity of cellulases would be present that would allow the co-culture to grow on cellulose instead of collapsing.
When $U$. maydis was added to the $T$. reesei culture after cellulase production had already started, itaconic acid production was successful. The influence of the different inoculation delays on both cellulase and itaconic acid production was surprisingly low (Fig. 6). Cellulase production of $T$. reese $i$ is directly proportional to the available concentration of the nitrogen source. Because of this, it would have been expected that earlier inoculation of $U$. maydis would reduce cellulase production because of the competition for nitrogen. In this case, due to an earlier limitation of nitrogen also an earlier onset of itaconic acid production would have been expected. However, this was clearly not the case, suggesting only a very low growth and nitrogen consumption by $U$. maydis. To analyze the growth of $U$. maydis, a differential fluorescent staining technique was developed to clearly discriminate $U$. maydis cells from T. reesei and thereby allow for manual cell counting of the $U$. maydis population (see material and methods). For the cultures with 3 and 4 days inoculation delay, $U$. maydis only grew very slowly before the first cellulose feed. Starting from an initial inoculation density of $0.8 \cdot 10^{7}$ cells $/ \mathrm{mL}$ (corresponding to a measured OD of 1.14 ), only a cell density of $2.7 \cdot 10^{7}$ and $1.7 \cdot 10^{7}$ cells $/ \mathrm{mL}$ 


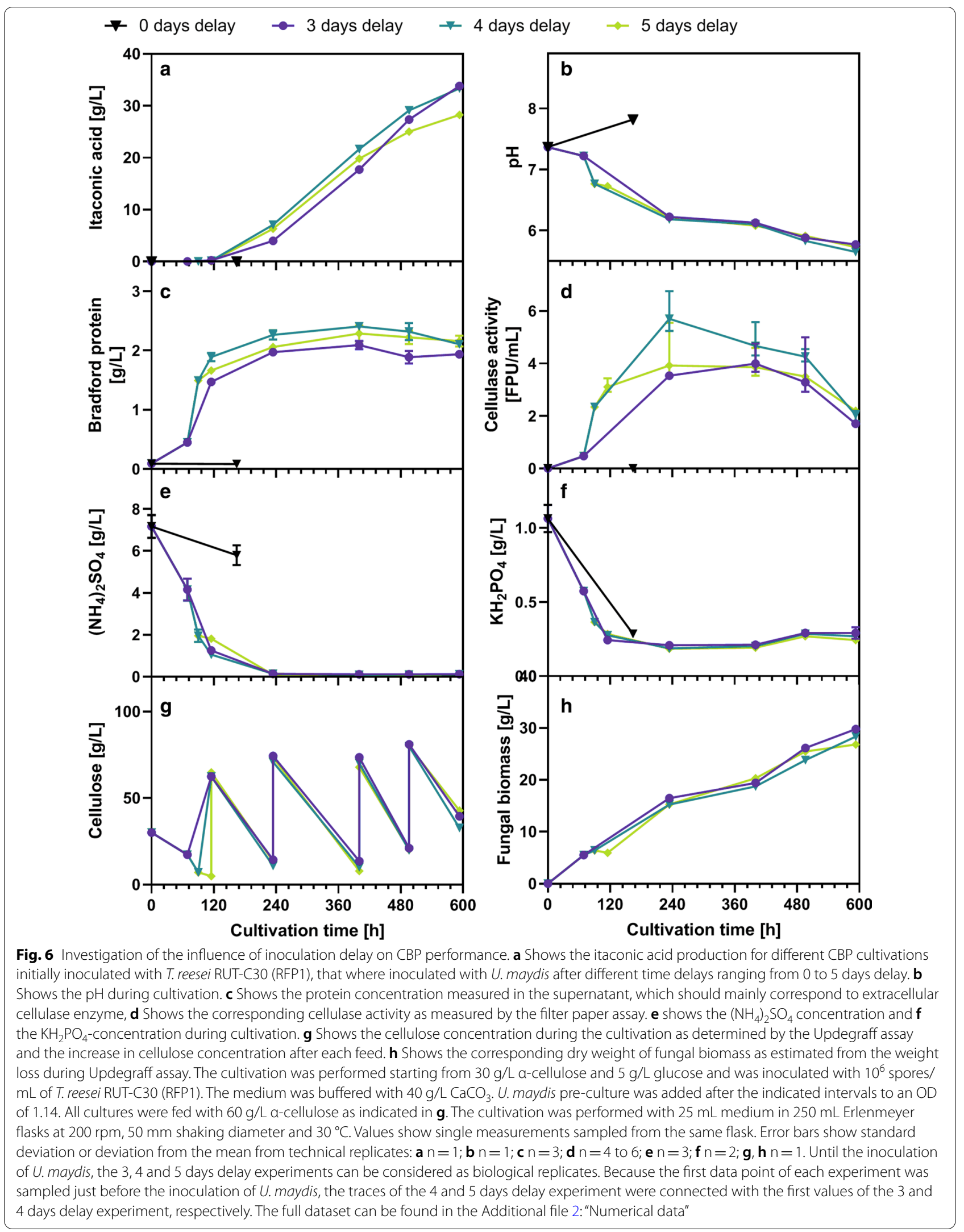


within $46 \mathrm{~h}$ and $25 \mathrm{~h}$ was reached, respectively, although the medium contained still all nutrients necessary for growth (Fig. 6e-g). The extent of growth inhibition becomes clearer in comparison to the growth of $U$. may$d i s$ in the instantly co-inoculated experiment. Here, $U$. maydis was able to grow to a cell density of $25 \cdot 10^{7}$ cells/ $\mathrm{mL}$ in $24 \mathrm{~h}$ with just $5 \mathrm{~g} / \mathrm{L}$ of glucose. For the experiments with inoculation delay, significant growth of $U$. maydis was only evident after increasing the carbon supply by feeding additional cellulose (Additional file 1: Figure S2). These phenomena may be explained by a higher affinity for sugars of $T$. reesei compared to $U$. maydis, enabling the former to out-compete the latter under sugar limitation. For reference, we observed $\mu_{\max }$ values of 0.17 and 0.21 for $T$. reesei and $U$. maydis, respectively, when grown in pure culture at $\mathrm{pH} 7$ in MES-buffered glucose media. Hence, under non-limited conditions $U$. maydis is the faster growing of both organisms. By feeding cellulose, the sugar concentration is increased, which enabled $U$. maydis to grow much faster.

Additionally, besides the temporal effect of the inoculation delay, there was also an unexpected viability effect that should have caused a growth benefit for $U$. maydis in the early inoculated experiments compared to the late inoculated experiments. The $U$. maydis inoculum was prepared from a YPD medium grown pre-culture that was washed twice with bi-distilled water and then stored as aqueous cell suspension at $0{ }^{\circ} \mathrm{C}$ for the different inoculation time points, so that the same stock could be used for all tested conditions. The viability of the aqueous inoculum was monitored for each inoculation time point by always inoculating a YPD medium filled flask in parallel to the CBP cultures and recording growth using online scattered light measurements. By observing an increase in the lag time with the age of the aqueous inoculum, it became clear that the viable cell density dropped significantly over time (Additional file 1: Figure S3). The increase in lag time by more than one doubling time $(3.5 \mathrm{~h})$ suggests at least a twofold difference in viable cell density. Despite the drop in viability, there was no impact on CBP performance. Thus, the sugar supply rate was the key factor determining population dynamics and sugar partitioning between $T$. reesei and $U$. maydis, while neither the inoculation delay nor inoculation density of $U$. maydis had a significant effect.

Also regarding itaconic acid productivity, the sugar supply rate (and thus, the cellulose hydrolysis rate) was most likely the limiting factor. For a glucose-based itaconic acid production reference, typically a cell density of $50 \cdot 10^{7}$ cells $/ \mathrm{mL}$ and a productivity of $0.77 \mathrm{~g} / \mathrm{L} / \mathrm{h}$ are reached under the investigated conditions (Additional file 1: Figure S4). Since the determined $U$. maydis cell density during CBP ranged from $10 \cdot 10^{7}$ to $30 \cdot 10^{7}$ cells/
$\mathrm{mL}$, a theoretical itaconic acid production capacity of 0.16 to $0.46 \mathrm{~g} / \mathrm{L} / \mathrm{h}$ was present in the CBP. The fact that only a maximum productivity of $0.10 \mathrm{~g} / \mathrm{L} / \mathrm{h}$ was reached in the fed-batch CBP indicates that the cells were not producing itaconate at maximum capacity, likely due to the above-mentioned competition for glucose.

As envisaged, the total average productivity (including the cellulase production phase) in this fed-batch experiment was indeed higher than in the previous batch experiment with 7 day inoculation delay (Table 2). However, this effect was not related exclusively to the smaller inoculation delay or an earlier onset of itaconic acid production. Instead, the productivity was generally slightly higher and was sustained for a longer period, so that the influence of the cellulase production phase duration on the total average itaconic acid productivity was minimized. This was due to the regular feeding of cellulose and thus mainly a benefit of fed-batch fermentation in contrast to batch fermentation. The key factor controlling the start of itaconic acid production was the time point of the first cellulose feeding, which in all cases was synchronized to 5 days after start of the experiment and thereby likely also synchronized the itaconic acid production. This feeding regime was chosen because a preliminary mass feeding of cellulose would have compromised cellulase production by $T$. reesei. An earlier start of itaconic acid production could therefore be at the expense of cellulase activity.

\section{Detailed online process monitoring during co-culture $\mathrm{CBP}$ using online respiratory analysis}

Up to now, consortium-based CBP has been proven successful only in academic research. One major obstacle for industrial application of such processes is a lack of suitable and established process control techniques. The substrate consumption for example is very difficult to assess in complex cultures containing solid cellulose particles. Here, the respiration rate of the fed-batch CBP was monitored online as a direct measure for microbial activity. As described in earlier studies $[49,56]$, cellulose consumption and thereby suitable time points for feeding fresh substrate could be estimated online based on the cumulative oxygen consumption. This way, intermittent starvation of the culture could be prevented (Fig. 7a, c).

The use of online respiration measurement further allowed to estimate the product formation online. Assuming the pure aerobic combustion of glucose as only carbon source for maintenance and biomass formation, the respiratory quotient can be considered to be 1 (Fig. 1, pathway C). During phases of significant formation of partially oxidized products such as itaconic acid, which is typically produced at a yield of $0.4 \mathrm{~g} / \mathrm{g}$ in $U$. maydis, the RQ should be even below 1. Pure itaconic 


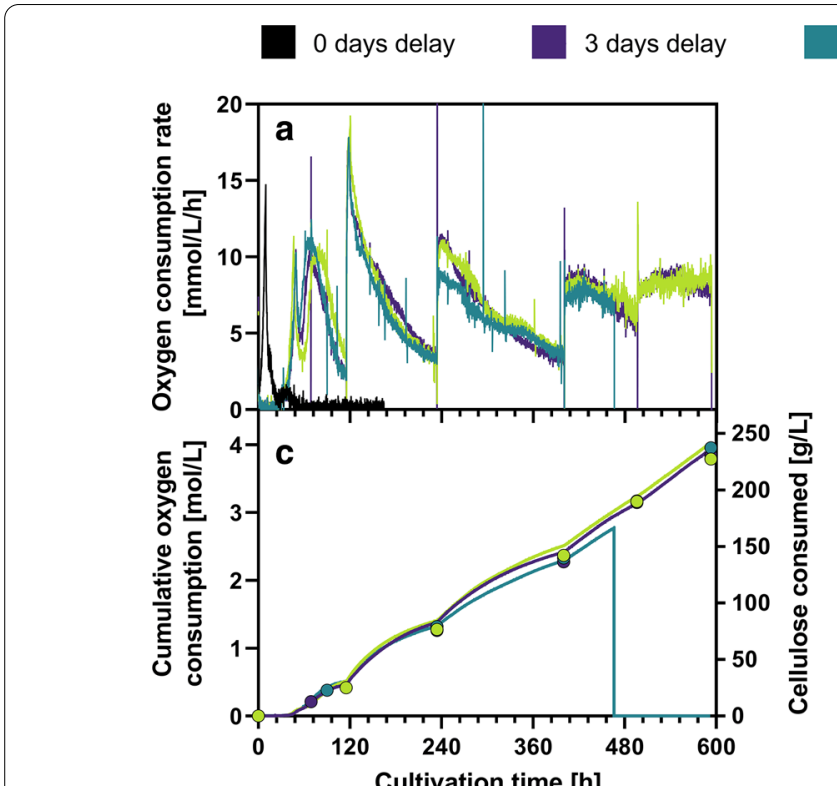

4 days delay $\quad 5$ days delay

Fig. 7 Respiration-based online process monitoring during co-culture CBP. a Shows the oxygen consumption rate. The first peak indicates the consumption of $5 \mathrm{~g} / \mathrm{L}$ glucose, the second peak marks the consumption of the initial cellulose. The following peaks were caused by the cellulose feeding; a sharp increase in oxygen consumption was observed after every cellulose feeding interval. b Shows the corresponding respiratory quotient as a rolling average of the original data for clarity and noise reduction. $\mathbf{c}$ shows the cumulative oxygen consumption as an indicator for cellulose consumption. The closed circles show the actual cellulose consumption as determined from offline measurements. $\mathbf{d}$ Shows the difference between cumulative oxygen consumption and cumulative $\mathrm{CO}_{2}$ evolution as an indicator for itaconic acid formation. Closed circles indicate corresponding itaconic acid concentrations as determined from offline measurements. Y-axis were scaled in a way that $1 \mathrm{mmol}^{\mathrm{CO}_{2}}$ evolution equals $1 \mathrm{mmol}$ itaconic acid produced. Because of a software bug, the 4 days delay experiment stopped recording after $468 \mathrm{~h}$. For comparison, values from a pure culture reference experiment of U. maydis grown in a glucose fed-batch can be found in Additional file 1: Figure S4

acid formation would cause an RQ of 0.67 (Fig. 1, pathway a). However, since $\mathrm{CaCO}_{3}$ was used for buffering of the cultures, the production of $1 \mathrm{~mol}$ itaconic acid would release an additional mole of $\mathrm{CO}_{2}$ by reacting with the carbonate, thereby increasing the RQ above 1 (Fig. 1, pathways a, b, blue values). This effect is depicted more clearly in Additional file 1: Figure S5, comparing the theoretical RQ in absence or in presence of $\mathrm{CaCO}_{3}$ in relation to the itaconic acid yield. Hence, an RQ above 1 in presence of $\mathrm{CaCO}_{3}$ indicates that itaconic acid production is ongoing, while a drop of RQ close to 1 indicates cessation of itaconic acid production. During the experiment, RQ values well above the theoretically expected values have been measured, because the used strain still produces considerable amounts of reduced by-products such as glycolipids, which result in an increased RQ [25, 57]. An explanation for this phenomenon is illustrated in Figure S5.

The profile of the RQ over time thereby serves as an indicator for the time-resolved itaconic acid yield during the process (Fig. 7b). While the global average itaconic acid yield was only $0.16 \mathrm{~g} / \mathrm{g}$, this averaged value likely results from dynamic fluctuations of phases with high yield $(0.4 \mathrm{~g} / \mathrm{g})$ and phases without itaconic acid production. The data suggest that the actual itaconic acid yield was highly dependent on the cellulose concentration and thus sugar supply rate. After each feeding, the RQ went up to a maximum of about 1.3 before gradually decreasing to values close to or even below 1 , where itaconic acid production likely stopped (Fig. 7b). When a surplus of substrate was available after a cellulose pulse, the yield approached values typically observed with glucose based fermentations, but then dropped as the substrate depleted. Thus, when the substrate supply was high, itaconic acid production was the dominant process, while respiration of $T$. reese $i$ and $U$. maydis became more dominant with low substrate supply. This implies that a certain threshold substrate supply rate has to be sustained in order to enable itaconic acid production and that the maximum itaconic acid yield is only achieved under carbon non-limited conditions. This observation fits well to the observed influence of sugar supply rate on substrate partitioning and population dynamics between $T$. reesei and $U$. maydis observed at the early phase of the fermentation.

Assuming i) a baseline RQ of 1 for both $T$. reesei and $U$. maydis; ii) that any surplus $\mathrm{CO}_{2}$ is derived from acid reaction with $\mathrm{CaCO}_{3}$ and iii) that itaconic acid is the only 
acid formed, the amount of itaconic acid produced can be directly estimated from the difference between cumulated $\mathrm{CO}_{2}$ evolution and the cumulated $\mathrm{O}_{2}$ uptake. Figure $7 \mathrm{~d}$ shows a comparison of itaconic acid production and online estimation based on respiration measurement. The axes are scaled in a way that $130 \mathrm{~g} / \mathrm{L}$ itaconic acid equals $1 \mathrm{~mol} / \mathrm{L} \mathrm{CO}_{2}$ difference, hence $1 \mathrm{~mol} \mathrm{CO}_{2}$ per mol itaconic acid $(130 \mathrm{~g} / \mathrm{mol})$. Although the online estimation did not fit exactly to the HPLC measurements, the method can give an approximation and a clear trend of itaconic acid production. Underestimation can be explained by either production of reduced storage molecules, $\mathrm{CO}_{2}$ fixation or non-respirative oxidation reactions while over-estimation is most likely a result of other organic acid by-products, which have been observed in the CBP cultures but not during itaconic acid production from glucose (Additional file 1: Table S6). The online estimation suggests that the time-resolved itaconic productivity (the slopes in Fig. $7 \mathrm{~d}$ ) reached values up to $2.2 \mathrm{mmol} / \mathrm{L} / \mathrm{h}$ (or $0.29 \mathrm{~g} / \mathrm{L} / \mathrm{h}$ ) after each cellulose feeding, which implies that the actual itaconic acid production potential present in the $\mathrm{CPB}$ was considerably higher than the achieved averaged value of $0.07 \mathrm{~g} / \mathrm{L} / \mathrm{h}$. These data suggest that if the duration of the feeding intervals of the cellulose are reduced, the space-time-yield could be increased up to fourfold, reducing the total process time to $240 \mathrm{~h}$. The best way to optimize the process would be an RQ-controlled automatic feeding of cellulose powder.

\section{Techno-economic perspective}

Nieder-Heitmann et al. performed a techno-economic analysis to compare sugar cane bagasse-based itaconic acid production via SHF to classical glucose-based production. Assuming an overall conversion yield of cellulose-rich sugarcane bagasse to itaconic acid between 0.086 and $0.188 \mathrm{~g} / \mathrm{g}$, a titer of $147 \mathrm{~g} / \mathrm{L}$ and a productivity of $1.15 \mathrm{~g} / \mathrm{L} / \mathrm{h}$, cellulosic itaconic acid would be already on-par or superior to glucose based itaconic acid [58]. While the calculated minimum selling price was most sensitive to yield and productivity, the titer was less important. It was shown that major economic burdens of the cellulosic SHF process were the high investment costs related to additional production facilities for separate hydrolysis and enzyme production as well as the energy requirement for the concentration of raw hydrolysates to the high sugar concentrations necessary for efficient itaconic acid production with $A$. terreus. Both of these major cost drivers were neutralized in the here presented SSF and CBP processes. Additional cost savings can be expected for the downstream processing as the itaconic acid precipitates in situ during fermentation, which makes product isolation less energy intense [54]. While the overall cellulose-to-itaconic acid conversion yield of
$0.17 \mathrm{~g} / \mathrm{g}$ in the fed-batch CBP already fits well into the economically viable scenario of Nieder-Heitmann et al., the productivity still needs to be significantly improved. However, a detailed techno-economic calculation for our case will be necessary to determine the minimum viable productivity, as cost savings from lower energy demand and lower investment costs will likely compensate to some degree for a lower productivity.

\section{Conclusion}

The capability of $U$. maydis to produce itaconic acid under glucose-limiting conditions in an SSF process was verified, achieving a yield of $0.38 \mathrm{~g} / \mathrm{g}$ using recalcitrant $\alpha$-cellulose. This yield is the highest ever achieved in an SSF process, and it is comparable to that achieved on glucose (Table 1 ). The compatibility of $U$. maydis with a living $T$. reesei culture was evaluated in a sequential coculture CBP and compared to an SSF process with undiluted $T$. reesei supernatant. Although the CBP process was inferior to the SSF configuration, a direct conversion of cellulose to a meaningful quantity of itaconic acid could be demonstrated for the first time. Improvement of substrate allocation to $U$. maydis will be a key strategy to maximize itaconic acid yield during CBP, with cellulose concentration being the main determining factor. This finding was further corroborated by online analysis of the metabolic processes during fed-batch CBP using online respiration measurements, which indicated that the time-resolved itaconic acid productivity and yield peaked shortly after feeding cellulose and dropped with the depletion of the cellulose. The proposed method for online process monitoring will be a valuable tool for future improvement of the process as the feeding regime can be adjusted precisely to maximize substrate availability and thereby minimize respiration. Another key variable that will be an obvious target for future research is the effect of nitrogen concentration, which ultimately limits cellulase formation as well as the cell density of $U$. maydis and might therefore significantly improve productivity. A remarkable itaconic acid titer of $33.8 \mathrm{~g} / \mathrm{L}$ could be reached with the fed-batch CBP strategy, which is on par with current SHF based results (Table1). Overall, this study demonstrates the applicability of $U$. maydis for consolidated bioprocessing of cellulosic biomass in coculture, thus further expanding the process window with this organism.

\section{Methods}

\section{Microorganisms}

T. reesei RUT-C30 (RFP1) (a red fluorescent proteinlabeled clone [13] of the standard RUT-C30 strain obtained from American Type Culture Collection ATTC 56,765$)$ was propagated at $30{ }^{\circ} \mathrm{C}$ on potato extract 
glucose agar medium (Roth, Karlsruhe, Germany) containing $40 \mathrm{~mL} / \mathrm{L}$ of carrot juice (BIOBIO, Marken-Discount AG \& Co. KG, Germany). P. verruculosum M28-10, kindly gifted by Dr. Gerhard Kerns (Saxon Institute for Applied Biotechnology, Leipzig, Germany), was propagated at $30{ }^{\circ} \mathrm{C}$ on medium containing $10 \mathrm{~g} / \mathrm{L}$ malt extract (Difco; Becton, Dickinson and Company, USA), $40 \mathrm{~mL} / \mathrm{L}$ carrot juice, $10 \mathrm{~g} / \mathrm{L}$ wheat bran (Alnatura, Darmstadt, Germany), $10 \mathrm{~g} / \mathrm{L} \alpha$-cellulose (Sigma-Aldrich, St. Louis, USA), $30 \mathrm{~g} / \mathrm{L}$ agar (Difco; Becton, Dickinson and Company, USA). Spores were harvested from agar plates using $10 \mathrm{~mL} 0.01 \%(\mathrm{v} / \mathrm{v})$ Tween 80 solution and washed twice with bi-distilled water. The spore concentration was determined in a Neubauer-Improved counting chamber (Superior Marienfeld, Lauda-Königshofen, Germany), adjusted to $10^{9}$ spores $/ \mathrm{mL}$ and stored at $4{ }^{\circ} \mathrm{C}$. This $1000 \times$ concentrated stock was used for inoculation all experiments.

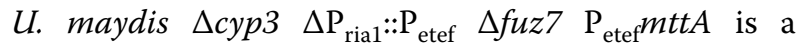
genetically engineered variant of $U$. maydis MB215 with enhanced itaconate production, reduced by-product formation, and stabilized morphology [28]. This strain was propagated at $30{ }^{\circ} \mathrm{C}$ on yeast extract peptone dextrose (YPD) agar plates. Liquid overnight cultures of $U$. maydis were grown from single agar plate colonies at $30^{\circ} \mathrm{C}$ in YPD medium. For inoculation of the experiments, YPD cultures were washed twice with bi-distilled water and used to inoculate the experiments to the final OD as indicated in the figure captions. For the initial SSF and batch CBP experiments, freshly prepared aqueous cell suspensions were used for inoculation. For the fed-batch CBP experiment, the same aqueous cell suspension stock was used for all tested inoculation delays and stored in an ice bath.

\section{Media and cultivation}

All experiments were performed in 250-mL Erlenmeyer flasks with $25 \mathrm{~mL}$ filling volume at $30{ }^{\circ} \mathrm{C}, 200 \mathrm{rpm}$ and $50 \mathrm{~mm}$ shaking diameter.

The itaconic acid production medium used in the initial SSF experiment was adopted from Geiser et al. [59]. Because the added cellulase-containing fermentation supernatants of the cellulase producers contained already residual $\mathrm{NH}_{4}^{+}, \mathrm{NH}_{4} \mathrm{Cl}$ was omitted. The medium contained $0.2 \mathrm{~g} / \mathrm{L} \mathrm{MgSO}_{4} \cdot 7 \mathrm{H}_{2} \mathrm{O}, 0.01 \mathrm{~g} / \mathrm{L}$ $\mathrm{FeSO}_{4} \cdot 7 \mathrm{H}_{2} \mathrm{O}, 0.5 \mathrm{~g} / \mathrm{L} \mathrm{KH}_{2} \mathrm{PO}_{4}, 1 \mathrm{~mL} / \mathrm{L}$ vitamin solution, $1 \mathrm{~mL} / \mathrm{L}$ trace element solution, and as buffer $19.5 \mathrm{~g} / \mathrm{L}$ (100 mM) 2-(N-morpholino) ethanesulfonic acid (MES) or $\mathrm{CaCO}_{3}$ as indicated in the figure captions. The $\mathrm{pH}$ of the MES stock solution was adjusted to 6.5 with $6 \mathrm{M}$ $\mathrm{NaOH}$ solution. The trace element solution contained $15 \mathrm{~g} / \mathrm{L}$ EDTA, $4.5 \mathrm{~g} / \mathrm{L} \mathrm{ZnSO}_{4} \cdot 7 \mathrm{H}_{2} \mathrm{O}, 1 \mathrm{~g} / \mathrm{L} \mathrm{MnCl}_{2} \cdot 4 \mathrm{H}_{2} \mathrm{O}$, $0.3 \mathrm{~g} / \mathrm{L} \quad \mathrm{CoCl}_{2} \cdot 6 \mathrm{H}_{2} \mathrm{O}, 0.3 \mathrm{~g} / \mathrm{L} \quad \mathrm{CuSO}_{4} \cdot 5 \mathrm{H}_{2} \mathrm{O}, 0.4 \mathrm{~g} / \mathrm{L}$
$\mathrm{Na}_{2} \mathrm{MoO}_{4} \cdot 2 \mathrm{H}_{2} \mathrm{O}, 4.5 \mathrm{~g} / \mathrm{L} \mathrm{CaCl} \cdot 2 \mathrm{H}_{2} \mathrm{O}, 3 \mathrm{~g} / \mathrm{L} \mathrm{FeSO}_{4} \cdot 7 \mathrm{H}_{2} \mathrm{O}$, $1 \mathrm{~g} / \mathrm{L} \mathrm{H}_{3} \mathrm{BO}_{3}$, and $0.1 \mathrm{~g} / \mathrm{L} \mathrm{KI}$. The vitamin solution contained $0.05 \mathrm{~g} / \mathrm{L}$ D-biotin, $1 \mathrm{~g} / \mathrm{L} \mathrm{D}$-calcium pantothenate, $1 \mathrm{~g} / \mathrm{L}$ nicotinic acid, $25 \mathrm{~g} / \mathrm{L}$ myo-inositol, $1 \mathrm{~g} / \mathrm{L}$ thiamine hydrochloride, $1 \mathrm{~g} / \mathrm{L}$ pyridoxol hydrochloride and $0.2 \mathrm{~g} / \mathrm{L}$ para-aminobenzoic acid. The medium was prepared as a $1.43 \times$ concentrated stock solution. The solution was filtered through a $0.2 \mu \mathrm{m}$ filter for sterilization. Before the experiment, the $1.43 \times$ concentrate was diluted to its original concentration by addition of sterile bidest water and sterile filtered cellulase-containing fermentation supernatants. The cellulase-containing fermentation supernatants of $T$. reesei RUT-C30 (RFP1) and P. verruculosum M28-10 were produced in a stirred tank fermentation as described in Additional file 1: S7. The necessary amount of cellulose was directly weighted into empty Erlenmeyer flasks ( $3 \mathrm{~g}$ Sigmacell or $3 \mathrm{~g} \alpha$-cellulose) and steam-sterilized at $121{ }^{\circ} \mathrm{C}$ as powder before the liquid medium was added. Both types of cellulose were purchased from Sigma-Aldrich (St. Louis, USA). For the single feeding event during the SSF cultivation, $1.5 \mathrm{~g}$ the corresponding cellulose was steam-sterilized as powder and added separately to each Erlenmeyer flask.

The medium for the co-culture CBP was based on a medium published by Pakula et al., which was modified for co-culture compatibility with $A$. terreus, $U$. maydis and $T$. reesei, enabling both itaconic acid and cellulase production by the respective organisms $[60,61]$. The final medium consisted of $\left(\mathrm{NH}_{4}\right)_{2} \mathrm{SO}_{4} 7.6 \mathrm{~g} / \mathrm{L}, \mathrm{KH}_{2} \mathrm{PO}_{4}$ $0.8 \mathrm{~g} / \mathrm{L}, \mathrm{MgSO}_{4} \cdot 7 \mathrm{H}_{2} \mathrm{O} 0.5 \mathrm{~g} / \mathrm{L}, \mathrm{CaCl}_{2} \cdot 2 \mathrm{H}_{2} \mathrm{O} 0.23 \mathrm{~g} / \mathrm{L}$, $\mathrm{NaCl} 0.05 \mathrm{~g} / \mathrm{L}, 5 \mathrm{~g} / \mathrm{L} \mathrm{CaCO}_{3}$, glucose $5 \mathrm{~g} / \mathrm{L}, \alpha$-cellulose $30 \mathrm{~g} / \mathrm{L}$, peptone ex casein $2 \mathrm{~g} / \mathrm{L}\left(\mathrm{N}-\mathrm{Z}-\mathrm{Amine}^{\circledR}\right.$ AS, Carl Roth, Karlsruhe, Germany), Tween $800.02 \%(\mathrm{v} / \mathrm{v})$, trace element solution $2.5 \mathrm{~mL} / \mathrm{L}$. The main solution without trace elements and cellulose was always prepared as a $2 \times$ concentrated stock solution that was set to $\mathrm{pH} 5.5$ with $5 \mathrm{M} \mathrm{NaOH}$. The solution was filtered through a $0.2 \mu \mathrm{m}$ filter for sterilization. Before the experiment, the $2 \times$ concentrate was diluted to its original concentration by addition of sterile bidest water and other supplementing solutions such as trace elements or glucose. The trace element solution $(400 \times$ concentrated $)$ had the following composition: citric acid $180 \mathrm{~g} / \mathrm{L}, \mathrm{Fe}_{2}\left(\mathrm{SO}_{4}\right)_{3} 2.29 \mathrm{~g} / \mathrm{L}$, $\mathrm{ZnSO}_{4} \cdot 7 \mathrm{H}_{2} \mathrm{O} 16 \mathrm{~g} / \mathrm{L}, \mathrm{CuSO}_{4} 2.05 \mathrm{~g} / \mathrm{L}, \mathrm{MnSO}_{4} \cdot 7 \mathrm{H}_{2} \mathrm{O}$ $1.6 \mathrm{~g} / \mathrm{L}, \mathrm{H}_{3} \mathrm{BO}_{3} 0.8 \mathrm{~g} / \mathrm{L}, \mathrm{CoCl}_{2} \cdot 6 \mathrm{H}_{2} \mathrm{O} 2.71 \mathrm{~g} / \mathrm{L}$.

For the batch CBP experiment, T. reesei was cultivated at $200 \mathrm{rpm}, 50 \mathrm{~mm}$ shaking diameter and $30{ }^{\circ} \mathrm{C}$ in three $1 \mathrm{~L}$ Erlenmeyer flasks with $100 \mathrm{~mL}$ filling volume for 7 days in the described co-culture medium buffered with $33 \mathrm{~g} / \mathrm{L} \mathrm{CaCO}_{3}$. Thereafter, the three cultures were pooled and phosphate and ammonium content of the culture was measured. Residual $\mathrm{NH}_{4}{ }^{+}$was equivalent to $1.2 \mathrm{~g} / \mathrm{L}$ $\mathrm{NH}_{4} \mathrm{Cl}$ and was not necessary to supplement before the 
inoculation of $U$. maydis since the $\mathrm{NH}_{4} \mathrm{Cl}$ concentration in itaconic acid production medium is only $0.8 \mathrm{~g} / \mathrm{L}$. Residual $\mathrm{KH}_{2} \mathrm{PO}_{4}$ was $0.18 \mathrm{~g} / \mathrm{L}$ and was supplemented to a final concentration of $0.5 \mathrm{~g} / \mathrm{L}$ to prevent preliminary phosphate limitation. For the CBP experiment, the T. reesei culture broth was distributed to three replicate Erlenmeyer flasks ( $25 \mathrm{~mL}$ each), for the corresponding SSF experiment, the residual $T$. reesei culture broth was sterile filtrated and also distributed into three replicate Erlenmeyer flasks $(25 \mathrm{~mL}$ each). The necessary amount of cellulose and $\mathrm{CaCO}_{3}$ was directly weighted into the empty Erlenmeyer flasks and steam-sterilized at $121{ }^{\circ} \mathrm{C}$ as powder before the liquid was added. Thereby, the cultures were supplemented with $120 \mathrm{~g} / \mathrm{L} \alpha$-cellulose and $33 \mathrm{~g} / \mathrm{L} \mathrm{CaCO}_{3}$.

For the fed-batch CBP, the $\mathrm{KH}_{2} \mathrm{PO}_{4}$ starting concentration in the co-culture medium was increased to $1.3 \mathrm{~g} / \mathrm{L}$ to anticipate the $\mathrm{KH}_{2} \mathrm{PO}_{4}$ supplementation that was necessary in the batch CBP. $\mathrm{CaCO}_{3}$ was increased to $40 \mathrm{~g} / \mathrm{L}$.

The reference cultivation of $U$. maydis with $50 \mathrm{~g} / \mathrm{L}$ glucose was performed in in the co-culture medium with only $1.5 \mathrm{~g} / \mathrm{L} \mathrm{NH}_{4} \mathrm{SO}_{4}, 0.5 \mathrm{~g} / \mathrm{L} \mathrm{KH}_{2} \mathrm{PO}_{4}$, without cellulose and buffered with $40 \mathrm{~g} / \mathrm{L} \mathrm{CaCO}_{3}$.

\section{Sampling}

1-mL samples were withdrawn from the same Erlenmeyer flasks during the cultivation (no sacrifice flasks). The weight of the Erlenmeyer flasks was determined before every sampling to correct the measured variables for evaporation. When necessary, bi-distilled water was added to compensate for significant evaporation.

\section{Analytics}

Phosphate was determined according a method for orthophosphate determination published by the United states EPA [62]. Ammonium was determined according to a modified version of the Berthelot reaction [63]. The protein concentration of the culture supernatant was determined by a Bradford assay [64] using Coomassie Plus $^{\mathrm{TM}}$ assay reagent (Thermo Scientific, Waltham, USA) and bovine serum albumin as standard. The measurement procedure was performed according to the manufacturer's manual for microtiter plates. Cellulase activity in the culture supernatant was measured by the standard filter paper activity (FPA) assay according to the method of Ghose [65] adapted by Xiao [66]. The assay was performed in a $60-\mu \mathrm{L}$ reaction volume in 96 -well conical bottom PCR plates.

Soluble sugars and metabolites including glucose, cellobiose, xylose as well as itaconic acid, citric acid, malic acid and succinic acid were determined via HPLC analysis. To dissolve potentially precipitated calcium itaconate, the broth was diluted $6 \times$ with $0.5 \mathrm{M} \mathrm{HCl}$. After centrifugation of the fermentation samples $(16,900 \mathrm{~g}$; $10 \mathrm{~min} ; 4{ }^{\circ} \mathrm{C}$ ) and a second centrifugation step of the resulting supernatant $(3,000 \mathrm{~g} ; 10 \mathrm{~min})$, the supernatant was analyzed by HPLC (Dionex HPLC UltiMate 3000, Thermo Scientific, Waltham, USA) at $65{ }^{\circ} \mathrm{C}$ using the following setup: Column: AMINEX Ion Exclusion HPX-87H, $300 \times 7.8 \mathrm{~mm}$ (Bio-Rad Laboratories GmbH, Munich, Germany); detectors: Dionex ${ }^{\mathrm{TM}}$ Ultimate 3000 UV/VIS detector (Thermo Scientific, Waltham, USA) at $210 \mathrm{~nm}$ and RI-101 refractory index detector (Shodex, Munich, Germany); mobile phase: $5 \mathrm{mM}$ sulfuric acid; flow rate: $0.7 \mathrm{~mL} / \mathrm{min}$.

For the standard determination of CDW in absence of cellulose particles, between 0.75 and $3 \mathrm{~mL}$ of sample were filled into pre-weighted conical bottom glass tubes and centrifuged $\left(20 \mathrm{~min}, 3,000 \mathrm{~g}, 4{ }^{\circ} \mathrm{C}\right.$ ). The supernatant was carefully pipetted off for other analytic procedures. The resulting pellet was washed two times by resuspension in $10 \mathrm{~mL}$ dest. water with subsequent centrifugation (20 min, $3000 \mathrm{~g}, 4{ }^{\circ} \mathrm{C}$ ) and careful removal of the water using a pipette connected via a collecting bottle to a vacuum pump. Thereafter, the washed pellet was dried overnight (at least $12 \mathrm{~h}$ ) in a Speedvac device under vacuum at $40{ }^{\circ} \mathrm{C}$ and $300 \mathrm{~g}$ acceleration. Finally, the glass tube containing the dried pellet was weighed on a microbalance and the CDW was calculated by subtracting the empty weight of the tube.

For the determination of CDW and residual cellulose in samples containing cellulose particles, a modified version of the Updegraff method adapted by Ahamed \& Vermette was used $[67,68]$. First, the total dry weight of all solids (TDW) was determined as described for the standard CDW determination above. The resulting dry pellet was then re-suspended in $3 \mathrm{~mL}$ of Updegraff reagent and incubated for $30 \mathrm{~min}$ in a boiling water bath with a marble on top of the glass tube to reduce evaporation. Thereby, the Updegraff reagent selectively dissolves the fungal biomass, leaving the cellulose intact. Updegraff reagent is a mixture of $10 \mathrm{~mL}$ conc. nitric acid and $100 \mathrm{~mL} 80 \%$ acetic acid. After the incubation, the suspension was mixed with $3 \mathrm{~mL} 96 \%$ ethanol to facilitate sedimentation of the cellulose and centrifuged $\left(20 \mathrm{~min}, 3000 \mathrm{~g}, 4^{\circ} \mathrm{C}\right)$. The resulting pellet was washed two times by resuspension in $10 \mathrm{~mL}$ dest. water with subsequent centrifugation $\left(20 \mathrm{~min}, 3000 \mathrm{~g}, 4{ }^{\circ} \mathrm{C}\right.$ ) and careful removal of the water using a pipette connected via a collecting bottle to a vacuum pump. Thereafter, the pellet was washed with $1 \mathrm{~mL} 70 \%$ ethanol without subsequent resuspension and dried overnight (at least $12 \mathrm{~h}$ ) in a Speedvac device under vacuum at $40{ }^{\circ} \mathrm{C}$ and $300 \mathrm{~g}$ acceleration. Finally, the glass tube containing the dried pellet was weighed on a microbalance and the weight of cellulose was calculated by subtracting the empty weight 
of the tube. The corresponding CDW was determined by subtracting the weight of cellulose from the TDW.

\section{Offgas analysis}

The offgas analysis was realized using a commercial Transfer-Rate Online Measurement (TOM) system (Kuhner, Birsfelden, Switzerland) equipped with a mass flow controller.

\section{Online scattered light measurements}

Online scattered light measurements were performed using the cell growth quantifier (CGQ) system (Aquila biolabs $\mathrm{GmbH}$, Baesweiler, Germany).

\section{Microscopy and $U$. maydis cell counting}

T. reese $i$ and $U$. maydis were microscopically discriminated by their differing cell wall composition. Therefore, samples were stained with a mixture calcofluor, which predominantly stains $\beta-1,4$-glucan and trypan blue, which predominantly stains chitin [69]. The sample suspensions were first diluted $1 / 10$ with bi-distilled water and then $1 / 10-1 / 20$ with the following staining solution: $10 \mu \mathrm{g} / \mathrm{mL}$ trypan blue and $10 \mu \mathrm{g} / \mathrm{mL}$ calcofluor in $20 \mathrm{mM}$ phosphate-citrate buffer $\mathrm{pH}$ 7.4. Finally, $11 \mu \mathrm{L}$ of the diluted and stained suspension were pipetted into wells of a $\mu$-Slide angiogenesis (ibidi GmbH, Gräfelfing, Germany) and analyzed at 10X magnification (Plan-Apochromat 10X objective with $1 \mathrm{X}$ tubelens optovar) by a ZEISS Axio Observer Z1 (Zeiss, Jena, Germany) inverted fluorescence microscope equipped with a Yokogawa CSU-X1 spinning disk unit. Calcofluor fluorescence was recorded with $405 \mathrm{~nm}$ laser excitation, RQFT 405/488/568/641 dichroitic mirror and BP 450/50 nm emission filter. Trypanblue fluorescence was recorded with $638 \mathrm{~nm}$ laser excitation, RQFT 405/488/568/641 dichroitic mirror and BP 690/50 nm emission filter. Per sample, a total of 8 different field of views were recorded. For extended focus depth, 5 slices covering a Z-dimension range of $32 \mu \mathrm{m}$ were recorded and processed into a maximum projection image. Besides the differing morphology, $U$. maydis yeast cells showed stronger trypan blue fluorescence relative to T. reesei hyphae, which allowed manual counting of the yeast cells in the images.

\section{Supplementary information}

Supplementary information accompanies this paper at https://doi. org/10.1186/s13068-020-01835-4.

Additional file 1. Supplementary materials.

Additional file 2. Numerical data.

\section{Abbreviations}

CBP: Consolidated bioprocessing; CDW: Cell dry weight; CGQ: Cell growth quantifier; EPA: Environmental Protection Agency; FPU: Filter paper unit; HPLC: High-pressure liquid chromatography; IA: Itaconic acid; MES: 2-(N-Morpholino) ethanesulfonic acid; OD: Optical density at $600 \mathrm{~nm}$; RFP: Red fluorescent protein; RQ: Respiratory quotient; SHF: Separate hydrolysis and fermentation; SSF: Simultaneous saccharification and fermentation; TDW: Total dry weight; TOM:Transfer-rate online measurement; YPD: Yeast extract peptone dextrose medium.

\section{Acknowledgements \\ We thank Elena Antonov for her former contributions to the project on co- culture-based consolidated bioprocessing itaconic acid within the Cluster of Excellence "Tailor-Made Fuels from Biomass". We thank Prof. Dr. Gerhard Kerns (Saxon Institute for Applied Biotechnology, Leipzig, Germany) for providing the $P$. verruculosum M28-10 strain.}

\section{Authors' contributions}

IS designed the study, performed the experiments, analyzed the data and drafted the manuscript. MR and LR supervised the study. HT developed the high-performance U. maydis $\Delta c y p 3 \Delta P_{\text {ria }:: .}: P_{\text {etef }} \Delta f$ fuz $7 P_{\text {etee }} m t t A$ strain under supervision of NW and LB. JB initiated the project. All authors participated in data interpretation and revised the manuscript. All authors read and approved the final manuscript.

\section{Funding}

Open Access funding enabled and organized by Projekt DEAL. The Clusters of Excellence TMFB 236"Tailor-Made Fuels from Biomass" and FSC 2186"The Fuel Science Center", which are funded by the Excellence Initiative by the German federal and state governments, are gratefully acknowledged for financial support. NW and HT acknowledge funding from the German Federal Ministry of Food and Agriculture (BMEL), through the Agency for Renewable Resources (FNR) as part of the ERA-IB project "TTRAFFIC" (FKZ 22030515).

\section{Availability of data and materials}

The data generated or analyzed during this study are included in this published article and its supplementary information files. Further datasets used and analyzed during the current study are available from the corresponding author on reasonable request.

\section{Ethics approval and consent to participate}

Not applicable.

\section{Consent for publication \\ Not applicable.}

\section{Competing interests}

The authors declare that they have no competing interests.

\section{Author details}

${ }^{1}$ Leibniz Institute for Natural Product Research and Infection Biology - HansKnöll-Institute, Jena, Germany. ${ }^{2}$ Faculty of Biological Sciences, FriedrichSchiller-University, Jena, Germany. ${ }^{3}$ Institute of Applied Microbiology - IAMB, Aachen Biology and Biotechnology - ABBt, RWTH Aachen University, Aachen, Germany. ${ }^{4}$ AVT-Biochemical Engineering, RWTH Aachen University, Aachen, Germany. ${ }^{5}$ Institute of Bio- and Geosciences IBG-1: Biotechnology, Forschungszentrum Jülich, Jülich, Germany.

Received: 17 August 2020 Accepted: 17 November 2020 Published online: 14 December 2020

\section{References}

1. De Carvalho JCM, Soccol CR. Biobased itaconic acid market and research trends - Is it really a promising chemical? Chim Oggi-Chem Today. 2018;36:56-8. 
2. Itaconic Acid Manufacturers, Suppliers and Exporters on Alibaba.com [Internet]. 2020. https://www.alibaba.com/trade/search?fsb=y\&Index Area $=$ product_en $\&$ Catld $=\&$ SearchText $=$ itaconic+acid. Accessed 14 Oct 2020.

3. ISA Daily Price [Internet]. 2020. https://www.isosugar.org/prices.php. Accessed 22 Oct 2020.

4. Nuss P, Gardner KH. Attributional life cycle assessment (ALCA) of polyitaconic acid production from northeast US softwood biomass. Int J Life Cycle Assessment. 2013;18(3):603-12.

5. da Cunha Cruz J, de Machado Castro A, Camporese Servulo EF. World market and biotechnological production of itaconic acid. 3 Biotech. 2018;8(3):138

6. Klement T, Büchs J. Itaconic acid-a biotechnological process in change. Bioresour Technol. 2013;135:422-31.

7. Kuenz A, Krull S. Biotechnological production of itaconic acid -things you have to know. Appl Microbiol Biotechnol. 2018;102(9):3901-14.

8. Geiser E, Przybilla SK, Friedrich A, Buckel W, Wierckx N, Blank LM, et al. Ustilago maydis produces itaconic acid via the unusual intermediate trans-aconitate. Microb Biotechnol. 2016;9(1):116-26.

9. Bafana R, Pandey RA. New approaches for itaconic acid production: bottlenecks and possible remedies. Crit Rev Biotechnol. 2018;38(1):68-82.

10. Karaffa L, Diaz R, Papp B, Fekete E, Sandor E, Kubicek CP. A deficiency of manganese ions in the presence of high sugar concentrations is the critical parameter for achieving high yields of itaconic acid by Aspergillus terreus. Appl Microbiol Biotechnol. 2015;99(19):7937-44.

11. Larsen $\mathrm{H}$, Eimhjellen KE. The mechanism of itaconic acid formation by Aspergillus terreus. 1. The effect of acidity. Biochem J. 1955;60(1):135-9.

12. Gyamerah $\mathrm{MH}$. Oxygen requirement and energy relations of itaconic acid fermentation by Aspergillus terreus NRRL 1960. Appl Microbiol Biotechnol. 1995;44(1):20-6.

13. Schlembach I. Investigations on the use of defined co-cultures for the consolidated bioprocessing of cellulose to itaconic acid. Aachen: RWTH Aachen University; 2019.

14. Regestein L, Klement T, Grande P, Kreyenschulte D, Heyman B, Massmann T, et al. From beech wood to itaconic acid: case study on biorefinery process integration. Biotechnol Biofuels. 2018;11:279.

15. Krull S, Eidt L, Hevekerl A, Kuenz A, Prüße U. Itaconic acid production from wheat chaff by Aspergillus terreus. Process Biochem. 2017;63:169-76.

16. Tippkötter N, Duwe A-M, Wiesen S, Sieker T, Ulber R. Enzymatic hydrolysis of beech wood lignocellulose at high solid contents and its utilization as substrate for the production of biobutanol and dicarboxylic acids. Biores Technol. 2014:167:447-55.

17. Liu Y, Liu G, Zhang J, Balan V, Bao J. Itaconic acid fermentation using activated charcoal-treated corn stover hydrolysate and process evaluation based on Aspen plus model. Biomass Convers Biorefin. 2019;10:463-70.

18. Wu X, Liu Q, Deng Y, Li J, Chen X, Gu Y, et al. Production of itaconic acid by biotransformation of wheat bran hydrolysate with Aspergillus terreus CICC40205 mutant. Bioresour Technol. 2017;241:25-34.

19. Kolláth IS, Molnár ÁP, Soós Á, Fekete E, Sándor E, Kovács B, et al. Manganese deficiency is required for high itaconic acid production from D-Xylose in Aspergillus terreus. Front Microbiol. 2019;10:1589.

20. Kerssemakers AAJD, Cassano MP, Yamakawa CK, Dragone G, Mussatto SI. Production of itaconic acid from cellulose pulp: feedstock feasibility and process strategies for an efficient microbial performance. Energies. 2020;13(7):1654.

21. Wierckx N, Agrimi G, Lubeck PS, Steiger MG, Mira NP, Punt PJ. Metabolic specialization in itaconic acid production: a tale of two fungi. Curr Opin Biotechnol. 2020;62:153-9.

22. Federal Institute-for Occupational Safety and Health. Classification of fungi into risk groups. Germany: Federal Institute for Occupational Safety and Health; 2016

23. Jäger G. Biocatalytic conversion of cellulose towards itaconic acid. Aachen: RWTH Aachen University; 2012.

24. Hosseinpour Tehrani $H$, Tharmasothirajan A, Track E, Blank LM, Wierckx $\mathrm{N}$. Engineering the morphology and metabolism of $\mathrm{pH}$ tolerant Ustilago cynodontis for efficient itaconic acid production. Metab Eng. 2019;54:293-300

25. Becker J, Hosseinpour Tehrani H, Gauert M, Mampel J, Blank LM, WierckX N. An Ustilago maydis chassis for itaconic acid production without byproducts. Microb Biotechnol. 2020;13(2):350-62.
26. Geiser E, Przybilla SK, Engel M, Kleineberg W, Buttner L, Sarikaya E, et al. Genetic and biochemical insights into the itaconate pathway of Ustilago maydis enable enhanced production. Metab Eng. 2016;38:427-35.

27. Krull S, Lünsmann M, Prüße U, Kuenz A. Ustilago Rabenhorstiana-an alternative natural itaconic acid producer. Fermentation. 2020;6(1):4.

28. Hosseinpour Tehrani H, Becker J, Bator I, Saur K, Meyer S, Rodrigues Loia AC, et al. Integrated strain- and process design enable production of $220 \mathrm{~g} \mathrm{~L}(-1)$ itaconic acid with Ustilago maydis. Biotechnol Biofuels. 2019;12:263.

29. Hosseinpour Tehrani H, Saur K, Tharmasothirajan A, Blank LM, Wierckx $\mathrm{N}$. Process engineering of $\mathrm{pH}$ tolerant Ustilago cynodontis for efficient itaconic acid production. Microb Cell Fact. 2019;18(1):213.

30. Couturier M, Navarro D, Olive C, Chevret D, Haon M, Favel A, et al. Postgenomic analyses of fungal lignocellulosic biomass degradation reveal the unexpected potential of the plant pathogen Ustilago maydis. BMC Genomics. 2012;13:57.

31. Mueller O, Kahmann R, Aguilar G, Trejo-Aguilar B, Wu A, de Vries RP. The secretome of the maize pathogen Ustilago maydis. Fungal Genet Biol. 2008;45(Suppl 1):S63-70.

32. Cano-Canchola C, Acevedo L, Ponce-Noyola P, Flores-Martinez A, Flores-Carreon A, Leal-Morales CA. Induction of lytic enzymes by the interaction of Ustilago maydis with Zea mays tissues. Fungal Genet Biol. 2000;29(3):145-51.

33. Zhao C, Chen $\mathrm{S}$, Fang H. Consolidated bioprocessing of lignocellulosic biomass to itaconic acid by metabolically engineering Neurospora crassa. Appl Microbiol Biotechnol. 2018;102(22):9577-84.

34. van der Straat L, Vernooij M, Lammers M, van den Berg W, Schonewille T, Cordewener J, et al. Expression of the Aspergillus terreus itaconic acid biosynthesis cluster in Aspergillus niger. Microb Cell Fact. 2014;13:11.

35. Hossain AH, van Gerven R, Overkamp KM, Lubeck PS, Taspinar H, Turker $\mathrm{M}$, et al. Metabolic engineering with ATP-citrate lyase and nitrogen source supplementation improves itaconic acid production in Aspergillus niger. Biotechnol Biofuels. 2019;12:233.

36. Xie H, Ma Q, Wei D, Wang F. Metabolic engineering of an industrial Aspergillus niger strain for itaconic acid production. 3 Biotech. 2020;10(3):113.

37. Geiser E, Reindl M, Blank LM, Feldbrugge M, Wierckx N, Schipper K. Activating intrinsic carbohydrate-active enzymes of the smut fungus ustilago maydis for the degradation of plant cell wall components. Appl Environ Microbiol. 2016;82(17):5174-85.

38. Geiser E, Wierckx N, Zimmermann M, Blank LM. Identification of an endo1,4-beta-xylanase of Ustilago maydis. BMC Biotechnol. 2013;13:59.

39. Stoffels $P$, Muller MJ, Stachurski S, Terfruchte M, Schroder S, Ihling N, et al. Complementing the intrinsic repertoire of Ustilago maydis for degradation of the pectin backbone polygalacturonic acid. J Biotechnol. 2020;307:148-63.

40. den Haan R, van Rensburg E, Rose SH, Görgens JF, van Zyl WH. Progress and challenges in the engineering of non-cellulolytic microorganisms for consolidated bioprocessing. Curr Opin Biotechnol. 2015;33:32-8.

41. Parisutham V, Kim TH, Lee SK. Feasibilities of consolidated bioprocessing microbes: from pretreatment to biofuel production. Bioresour Technol. 2014;161:431-40.

42. Zuroff TR, Xiques SB, Curtis WR. Consortia-mediated bioprocessing of cellulose to ethanol with a symbiotic Clostridium phytofermentans/yeast co-culture. Biotechnol Biofuels. 2013;6(1):59.

43. Shahab RL, Luterbacher JS, Brethauer S, Studer MH. Consolidated bioprocessing of lignocellulosic biomass to lactic acid by a synthetic fungal-bacterial consortium. Biotechnol Bioeng. 2018;115(5):1207-15.

44. Scholz SA, Graves I, Minty JJ, Lin XN. Production of cellulosic organic acids via synthetic fungal consortia. Biotechnol Bioeng. 2018;115(4):1096-100.

45. Minty JJ, Singer ME, Scholz SA, Bae CH, Ahn JH, Foster CE, et al. Design and characterization of synthetic fungal-bacterial consortia for direct production of isobutanol from cellulosic biomass. Proc Natl Acad Sci USA. 2013;110(36):14592-7.

46. Krull S, Hevekerl A, Kuenz A, Prüße U. Process development of itaconic acid production by a natural wild type strain of Aspergillus terreus to reach industrially relevant final titers. Appl Microbiol Biotechnol. 2017;101(10):4063-72.

47. Li X, Zheng K, Lai C, Ouyang J, Yong Q. Improved itaconic acid production from undetoxified enzymatic hydrolysate of steam-exploded corn stover using an Aspergillus terreus mutant generated by atmospheric and room temperature plasma. BioResources. 2016;11(4):12. 
48. Yang J, Xu H, Jiang J, Zhang N, Xie J, Zhao J, et al. Itaconic acid production from undetoxified enzymatic hydrolysate of bamboo residues using Aspergillus terreus. Biores Technol. 2020;307:123208.

49. Antonov E, Schlembach I, Regestein L, Rosenbaum MA, Buchs J. Process relevant screening of cellulolytic organisms for consolidated bioprocessing. Biotechnol Biofuels. 2017;10:106.

50. Voll A, Klement T, Gerhards G, Buechs J, Marquardt W. Metabolic modelling of itaconic acid fermentation with ustilago maydis. Chem Eng Trans. 2012:27:367-72.

51. Klein-Marcuschamer D, Oleskowicz-Popiel P, Simmons BA, Blanch HW. The challenge of enzyme cost in the production of lignocellulosic biofuels. Biotechnol Bioeng. 2012;109(4):1083-7.

52. Antonov E, Wirth S, Gerlach T, Schlembach I, Rosenbaum MA, Regestein $L$, et al. Efficient evaluation of cellulose digestibility by Trichoderma reese Rut-C30 cultures in online monitored shake flasks. Microb Cell Fact. 2016;15(1):164.

53. Hosseinpour Tehrani H, Geiser E, Engel M, Hartmann SK, Hossain AH, Punt PJ, et al. The interplay between transport and metabolism in fungal itaconic acid production. Fungal Genet Biol. 2019;125:45-52.

54. Magalhães Al, de Carvalho JC, Medina JDC, Soccol CR. Downstream process development in biotechnological itaconic acid manufacturing. Appl Microbiol Biotechnol. 2017;101(1):1-12.

55. Li J, Lin L, Sun T, Xu J, Ji J, Liu Q, et al. Direct production of commodity chemicals from lignocellulose using Myceliophthora thermophila. Metab Eng. 2019. https://doi.org/10.1016/j.ymben.2019.05.007.

56. Müller MJ, Stachurski S, Stoffels P, Schipper K, Feldbrügge M, Büchs J. Online evaluation of the metabolic activity of Ustilago maydis on (poly) galacturonic acid. J BiolEng. 2018;12(1):34.

57. Klement T, Milker S, Jäger G, Grande PM, de Domínguez María P, Büchs J. Biomass pretreatment affects Ustilago maydis in producing itaconic acid. Microb Cell Fact. 2012;11(1):43.

58. Nieder-Heitmann M, Haigh KF, Görgens JF. Process design and economic analysis of a biorefinery co-producing itaconic acid and electricity from sugarcane bagasse and trash lignocelluloses. Biores Technol. 2018;262:159-68.

59. Geiser E, Wiebach V, Wierckx N, Blank LM. Prospecting the biodiversity of the fungal family Ustilaginaceae for the production of value-added chemicals. Fungal Biol Biotechnol. 2014;1:2
60. Pakula TM, Salonen K, Uusitalo J, Penttila M. The effect of specific growth rate on protein synthesis and secretion in the filamentous fungus Trichoderma reesei. Microbiology. 2005;151(Pt 1):135-43.

61. Antonov E. Single reactor approach for platform chemical production from cellulose using a mixed culture. Germany: RWTH Aachen University; 2017

62. United states environmental protection agency. Method 365.3: phosphorous, all forms (Colorimetric, ascorbic acid, two reagent). Methods for chemical analysis of water and wastes. USA: Office of Research and Development; 1983. p. 3653-63.

63. Krom MD. Spectrophotometric determination of ammonia: a study of a modified Berthelot reaction using salicylate and dichloroisocyanurate. The Analyst. 1980;105(1249):305-16.

64. Bradford MM. A rapid and sensitive method for the quantitation of microgram quantities of protein utilizing the principle of protein-dye binding. Anal Biochem. 1976;72(1):248-54

65. Ghose T. Measurement of cellulase activities. Pure Appl Chem. 1987;59(2):257-68.

66. Xiao Z, Storms R, Tsang A. Microplate-based filter paper assay to measure total cellulase activity. Biotechnol Bioeng. 2004;88(7):832-7.

67. Updegraff DM. Semimicro determination of cellulose in biological materials. Anal Biochem. 1969;32(3):420-4.

68. Ahamed A, Vermette P. Culture-based strategies to enhance cellulase enzyme production from Trichoderma reesei RUT-C30 in bioreactor culture conditions. Biochem Eng J. 2008;40(3):399-407.

69. Liesche J, Marek M, Günther-Pomorski T. Cell wall staining with Trypan blue enables quantitative analysis of morphological changes in yeast cells. Front Microbiol. 2015. https://doi.org/10.3389/fmicb.2015.00107.

\section{Publisher's Note}

Springer Nature remains neutral with regard to jurisdictional claims in published maps and institutional affiliations.
Ready to submit your research? Choose BMC and benefit from:

- fast, convenient online submission

- thorough peer review by experienced researchers in your field

- rapid publication on acceptance

- support for research data, including large and complex data types

- gold Open Access which fosters wider collaboration and increased citations

- maximum visibility for your research: over $100 \mathrm{M}$ website views per year

At BMC, research is always in progress.

Learn more biomedcentral.com/submissions 